Universidad de Lima

Escuela de Posgrado

Maestría en Tributación y Política Fiscal

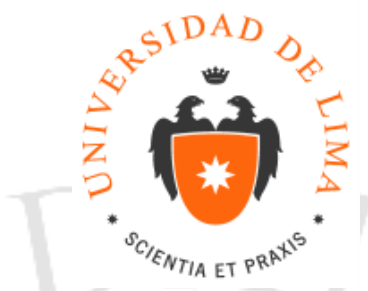

\title{
APLICACIÓN DEL CRÉDITO INDIRECTO EN EL PERÚ COMO MECANISMO PARA EVITAR LA DOBLE IMPOSICIÓN ECONÓMICA
}

Trabajo de Investigación presentado para optar el Grado Académico de Maestro en Tributación y Política Fiscal

Olga Soledad Sanchez Chanduvi

Código 20132490

Mónica Nancy Yaguas Gargate

Código 201222461

\section{Asesores}

Dra. Carla Mares Ruiz

Dr. Fernando Nuñez Ciarella

Lima - Perú

Noviembre 2017 


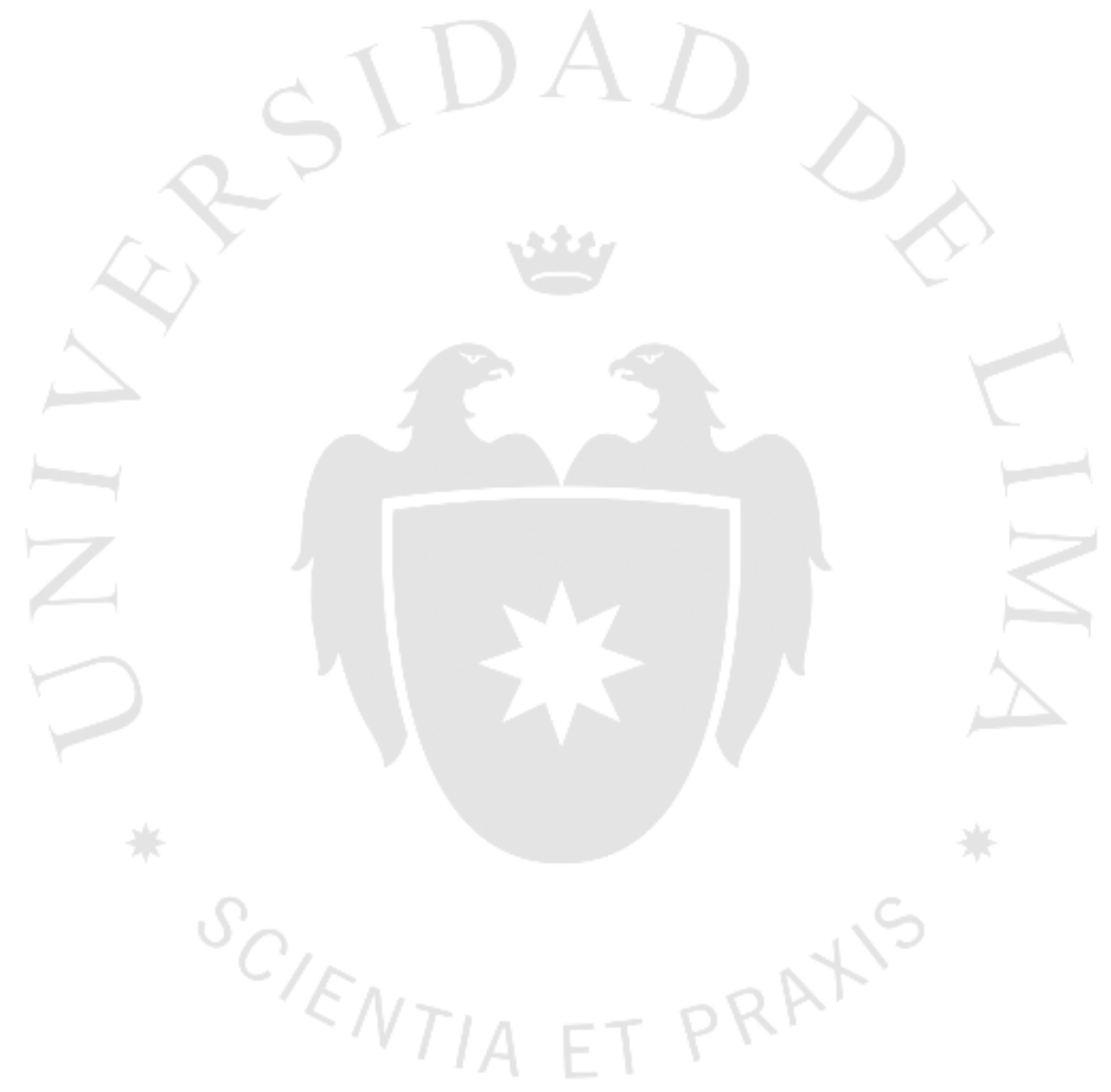




\section{APLICACIÓN DEL CRÉDITO INDIRECTO EN EL PERÚ COMO MECANISMO PARA EVITAR LA DOBLE IMPOSICIÓN ECONÓMICA}




\section{TABLA DE CONTENIDO}

INTRODUCCIÓN 1

CAPÍTULO I: ASPECTOS PRELIMINARES SOBRE LA PROBLEMÁTICA DE LA DOBLE IMPOSICIÓN ECONÓMICA ............................................................4

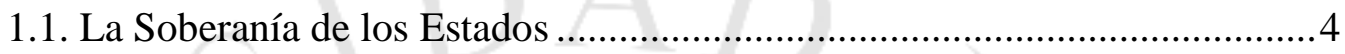

1.2. Los criterios de sujeción del impuesto a la renta.......................................5

1.3. Límites discrecionales del "criterio de mínima conexión territorial”...........6

1.4. El problema de la doble imposición internacional ....................................

1.4.1. Concepto de doble imposición internacional.......................................

1.4.2. Modalidades de la doble imposición .................................................... 9

1.4.2.1. Doble imposición económica ........................................................ 9

1.4.2.2. Doble imposición jurídica ............................................................ 9

1.4.3. Mecanismos para evitar la doble imposición .......................................... 10

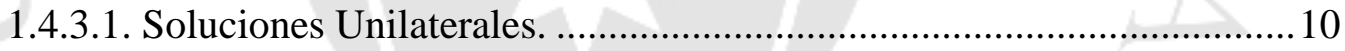

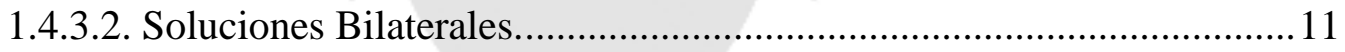

1.4.3.3. Soluciones Multilaterales. .............................................................. 13

1.4.4. Métodos para eliminar la doble imposición. ......................................... 13

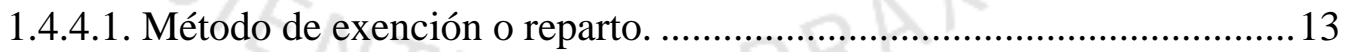

1.4.4.2. Método de imputación. ........................................................................ 14

1.4.5. Método para evitar la doble imposición en la Legislación Interna...........15

1.4.5.1. Aplicación del crédito pagado en el exterior según la Ley del Impuesto a la Renta.

CAPÍTULO II: TRATAMIENTO DEL CRÉDITO EN EL PERÚ Y EN LA

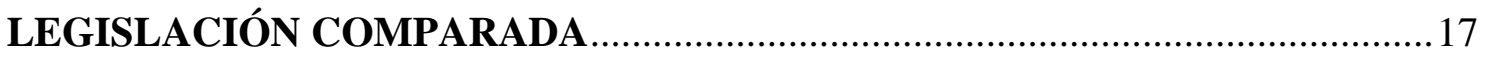


2.1.1.El crédito tributario indirecto en el Perú

2.1.2.Posibilidad de deducir como gasto los impuestos pagados en el exterior que no pueden ser utilizados como crédito

2.1.3.Análisis del Informe emitido por el MEF, $N^{\circ} 147-2014-E F / 61.01$

2.1.4.Inversiones en el extranjero - sucursales vs. Subsidiarias: Aplicación del crédito

2.1.5.El crédito tributario indirecto en los CDI suscritos por el Perú. .30

2.1.6.La necesidad de contar con normas internas para poder aplicar el crédito indirecto previsto en los Convenios Internacionales

2.2. Régimen de transparencia fiscal internacional y la aplicación del crédito indirecto

2.2.1.Crédito por impuesto pagado en el exterior..............................................36

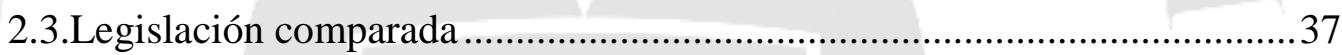

2.3.1. Tratamiento del crédito indirecto en Colombia .......................................37

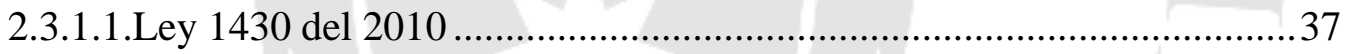

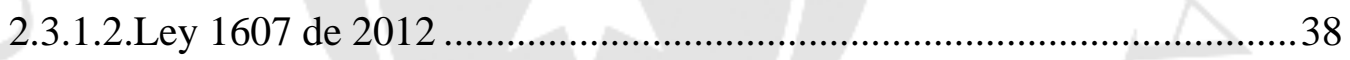

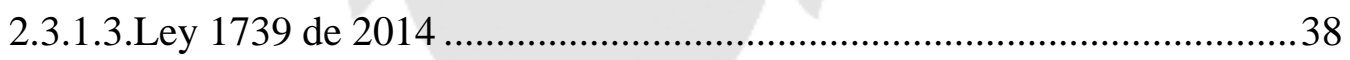

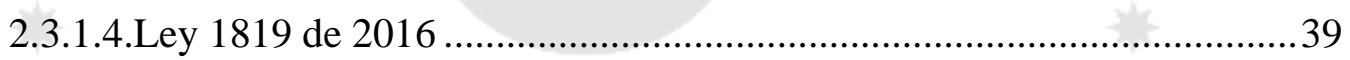

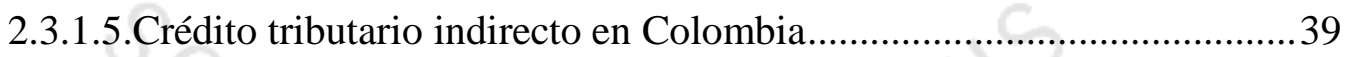

2.3.2. Tratamiento del crédito indirecto en Chile .............................................42

2.3.2.1. Crédito por impuestos soportados en el extranjero ............................. 42

2.3.2.2.Crédito Total Disponible (en adelante CDT) …...................................43

2.3.2.3.Registro de Inversiones en el Extranjero .............................................43

2.3.2.4.Tratamiento del Crédito por IPE respecto de países con los cuales no

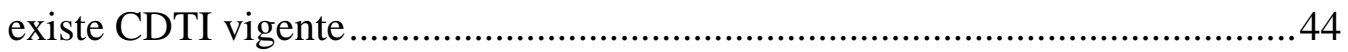

2.3.2.5.Determinación del CTD por dividendos o retiros de utilidades ............44 


\section{CAPÍTULO III: ASPECTOS A CONSIDERAR EN LA IMPLEMENTACIÓN}

DEL MECANISMO DEL CRÉDITO INDIRECTO EN EL PERÚ ........................ 48

3.1.Análisis del costo-beneficio de la incorporación del crédito indirecto en el

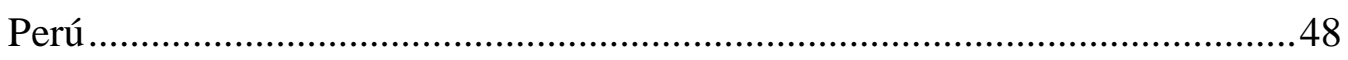

3.2.Aplicación del crédito indirecto - Caso Práctico ....................................... 48

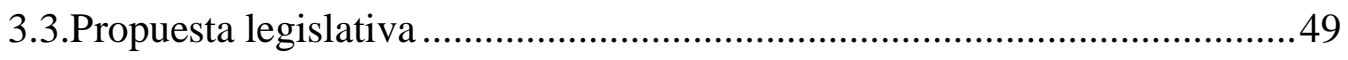

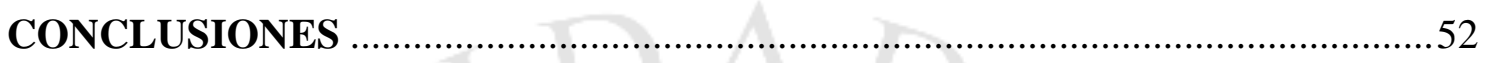




\section{ÍNDICE DE TABLAS}

Tabla 2.1 Diferencias de invertir entre una sucursal y una subsidiaria.

Tabla 2.2 Esquema tributario de Colombia

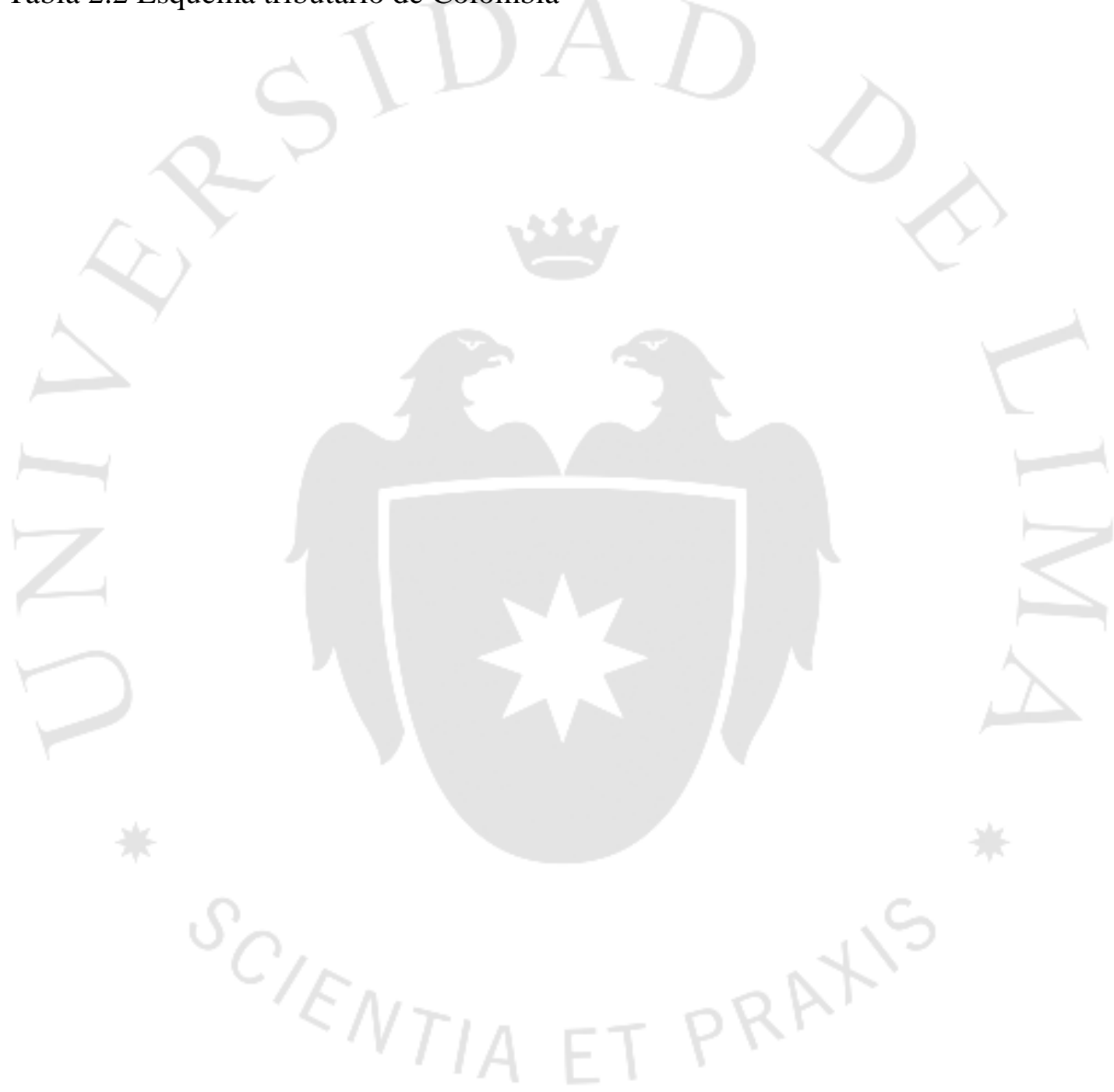




\section{ÍNDICE DE FIGURAS}

Figura 2.1. Tratamiento del Crédito Indirecto en Colombia.

Figura 2.2. Régimen de Transparencia Fiscal.

Figura 2.3. Esquema tributario de Colombia.

Figura 2.4 Determinación del crédito por dividendos

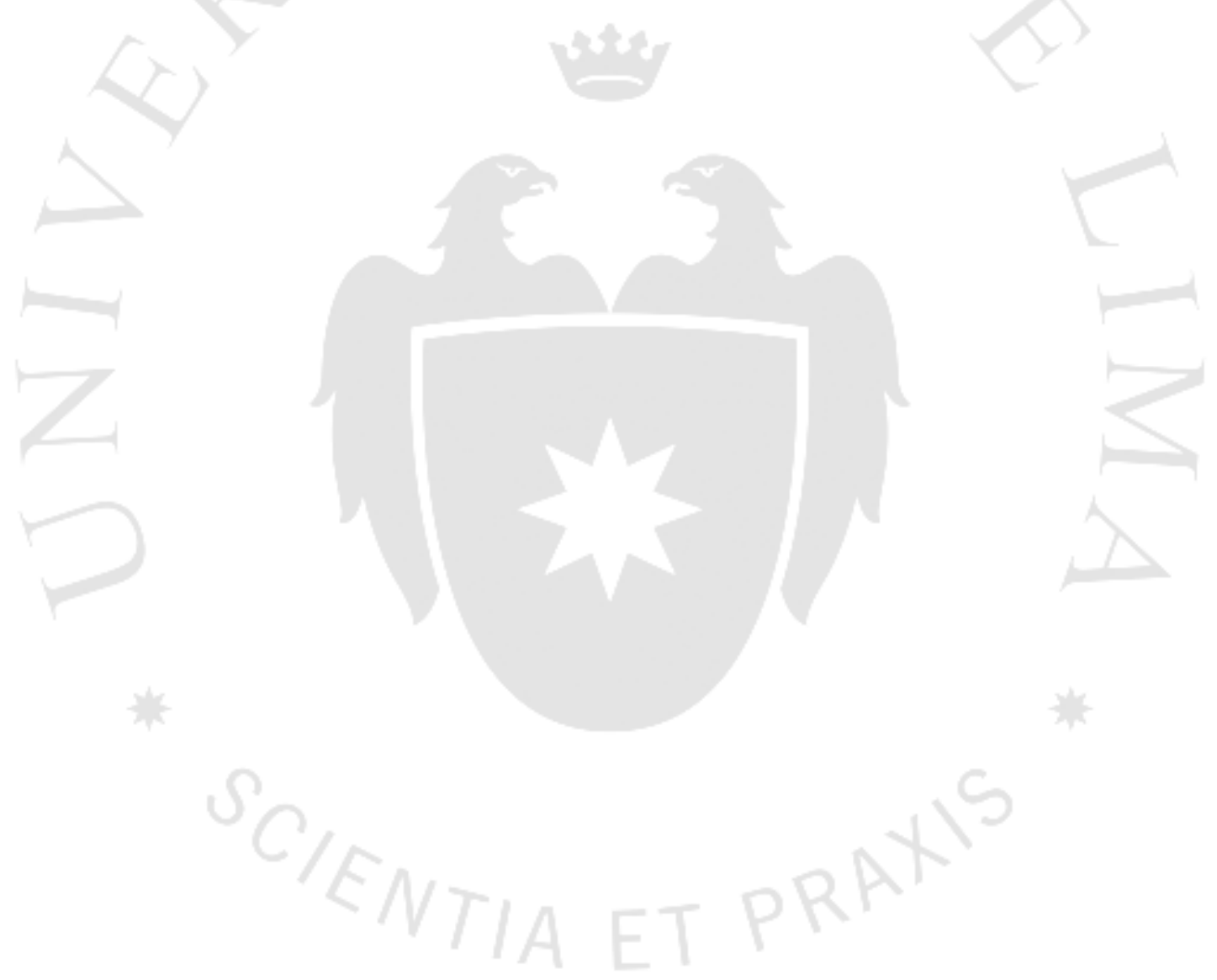




\section{INTRODUCCIÓN}

Hoy en día, los países adoptan diferentes medios en los sistemas de tributación internacional para hacer frente a los casos de doble imposición, y así poder aliviar sus efectos y, por qué no, eliminarlos. Para ello, incorporan en sus legislaciones internas mecanismos unilaterales, bilaterales y/o multilaterales.

Uno de los mecanismos más empleados para evitar las situaciones de doble imposición tributaria, es el del crédito. El Perú utiliza este sistema unilateral, mediante el cual, se les permite a los residentes de un país aplicar contra su Impuesto a la Renta local el impuesto que hayan pagado en el exterior sobre las rentas de fuente extranjera gravadas en el país.

En nuestra legislación, el tratamiento del crédito es regulado en el inciso e) del artículo 88 de la Ley del Impuesto a la Renta, pero sólo se reconoce la aplicación del crédito tributario directo. Cuando se habla del crédito por el impuesto que se paga en el exterior, nos referimos a que un país A exportador de la inversión, le concede al contribuyente $\mathrm{B}$ una deducción que equivale a los impuestos que este haya pagado en el exterior, debido a la generación de rentas fuera del país. Se debe acotar que este crédito se aplica con ciertas restricciones propias de cada sistema tributario.

Si la deducción a la cual se ha hecho referencia en el párrafo anterior, se refiere a los impuestos a los que está sometido en el extranjero el mismo sujeto que aplica el crédito en el país de la residencia (véase el ejemplo de Empresa Inca Perú que brinda servicios a su cliente del exterior Empresa Viva Alemania) y la retribución va estar sujeta a retenciones de impuestos en el país de esta última, éste es el caso del crédito directo que regula nuestra norma tributaria.

Pero, ¿qué sucede con el crédito tributario que se compone con los impuestos que paga un sujeto técnicamente distinto al que lo vaya aplicar, referidos a unas mismas rentas?, por ejemplo, el caso de las utilidades que se gravan cuando son generadas por el país de la fuente y luego nuevamente cuando son recibidas como dividendos en el país en el que se reside; este vendría a ser el caso de la aplicación del crédito indirecto, el cual, 
sin duda, aliviaría la doble imposición económica y que actualmente no contempla la Ley del Impuesto a la Renta.

Una de las grandes consecuencias de la ausencia de este mecanismo unilateral es no contribuir a fomentar la inversión en el exterior.

Entendemos que no es fácil que se puedan estructurar normas para una adecuada regulación del crédito tributario indirecto; es más, a nivel internacional, esta es una de las tareas más complejas de los países que optan por implementar el sistema de créditos por impuestos pagados en el exterior dentro de su regulación normativa, ya que se debe ser específico al momento de calcular la atribución precisa de la parte del impuesto extranjero que incidirá sobre los dividendos distribuidos y las posibles diferencias temporales que surgen de la obtención de la renta en el país de la fuente y la remisión efectiva de los dividendos al país de la residencia, tomando en cuenta que los ingresos se medirán en distintas monedas y bajo principios contables diferentes pertenecientes a ambas jurisdicciones.

Ello, lejos de desalentarnos, debería ser un motivo de avance en cuanto al tratamiento de normas tributarias, puesto que el escenario económico actual justificaría con creces el esfuerzo de que nuestros legisladores puedan diseñar una fórmula legal que incorpore el crédito indirecto en nuestra legislación. Como bien sostiene la doctrina nacional, al hablar sobre las inversiones peruanas en el exterior, el que se reconozca únicamente el crédito directo derivado de impuestos a la renta pagados en el exterior por las sociedades, filiales residentes en el extranjero, y no la deducción de créditos indirectos, ocasiona una doble imposición económica internacional y dificulta enormemente la repatriación de dividendos obtenidos en el exterior.

En adición a lo anterior, nuestra norma debe incorporar el crédito indirecto no solo porque esto aliviaría la doble imposición económica, sin perjuicio de las ventajas tributarias que puede traer operar en el extranjero mediante una subsidiaria; sino que también, está demostrado en el Derecho comparado, que la inexistencia del crédito indirecto discrimina a favor del sujeto que opera en el exterior mediante una sucursal (que para estos efectos equivale a operar directamente), frente al que lo hace mediante una subsidiaria.

Además, la ausencia de mecanismos de crédito indirecto obligaría a las empresas a adoptar a la sucursal como vehículo de inversión en el extranjero, toda vez que, al 
tratarse de un mismo ente, los impuestos pagados por la sucursal podrían ser utilizados como crédito por la empresa matriz.

Ahora bien, si analizamos la conveniencia de permitir el crédito indirecto, desde un punto de vista pro recaudador, entonces diríamos que su incorporación implica una pérdida en la recaudación interna tributaria. Pero basta con alegar que el propio Estado se ha obligado vía convenios internacionales a admitirlo, para que dicha postura quede descartada. A ello cabe añadir que dicha visión queda sin efecto, pues extender y promover la aplicación del crédito indirecto tendría un impacto positivo en el incremento de las inversiones peruanas en el exterior, el crecimiento económico del país, la mejora en la imagen del Perú como nación que respeta y promueve sus convenios tributarios, y eventualmente, incentivar a determinados contribuyentes (por ejemplo, personas naturales) a repatriar y declarar los rendimientos de sus inversiones, entre otros beneficios.

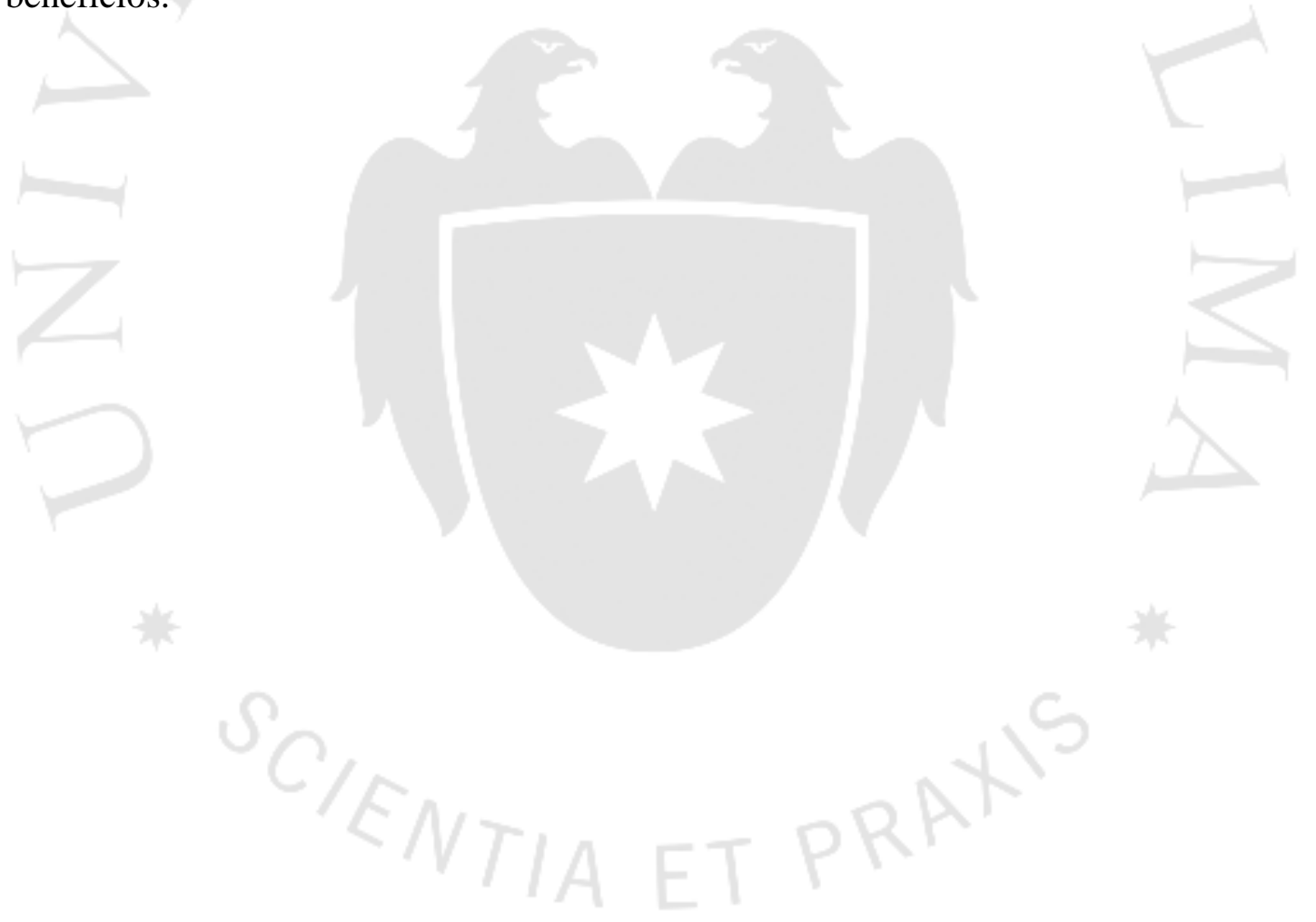




\section{CAPÍTULO I: ASPECTOS PRELIMINARES SOBRE LA PROBLEMÁTICA DE LA DOBLE IMPOSICIÓN ECONÓMICA}

\subsection{La Soberanía de los Estados}

Cada estado dicta sus normas tributarias de forma independiente en ejercicio de su soberanía, los Estados se reconocen recíprocamente como soberanos en un plano de igualdad, actuando como titulares de un poder independiente, compartido por muchos entes iguales. Como afirma Villagra (2008):

(...) La soberanía en general y no exclusivamente desde el plano tributario es un atributo del poder del Estado y significa que dicho poder es absoluto. La jurisdicción es un aspecto de la soberanía, un atributo esencial de ella, coexistente, que consiste en el ejercicio del poder soberano del Estado mediante sus órganos de gobierno (pág. 18).

Tejeiro (2003) señala: "La jurisdicción es ejercida en función al territorio y a la nacionalidad:

- En el territorio del Estado sobre las personas que en él habitan, tanto nacionales como extranjeros.

- Respecto de ciertas consecuencias, producidas dentro del territorio por personas que actúan fuera de él.

- Sobre los propios nacionales ubicados en terceros estados".

Según el artículo 54 de nuestra Constitución Política del Perú de 1993 el territorio “(...) comprende el suelo, el subsuelo, el dominio marítimo, y el espacio aéreo que los cubre"; es decir, viene a ser el ámbito espacial en la que el Estado ejerce su soberanía excluyendo a terceros países de ese mismo espacio.

En principio, el Estado está facultado para imponer carga tributaria a sus nacionales; pero a su vez, existen teorías sobre la jurisdicción tributaria de los Estados que justifican el derecho a gravar a extranjeros, las cuales son mencionadas por Villagra (2008): 
"En correspondencia a lo expuesto en los párrafos anteriores, la teoría de la soberanía es la que prima, frente a las teorías del realismo o empírica, la ética o retributiva y la contractual, conforme se simplifica a continuación:

- La teoría empírica niega la posibilidad de que el Estado pueda ejercer poder fuera de sus fronteras; sin embargo, la realidad demuestra lo contrario.

- La teoría ética, por su parte, encuentra en la tributación una retribución por los beneficios que el contribuyente recibe del Estado; sin embargo, al tener a la justicia como su fundamento, esta teoría involucra conceptos subjetivos que podrían conducir a especulaciones metafísicas alejadas de lo jurídico.

- La teoría contractual que identifica a la tributación como un pago o compensación por los bienes recibidos por el Estado impositor deviene inconsistente, en tanto en la tributación se prescinde del consentimiento voluntario propio del contrato" (pág. 18 y 19$)$.

\subsection{Los criterios de sujeción del impuesto a la renta}

A fin de que un Estado pueda someter a gravamen una riqueza, es necesario un vínculo entre el Estado y el sujeto que la manifiesta; estos vínculos se denominan criterios de sujeción.

García Mullin (1980) afirma:

"En efecto, para que un enriquecimiento calificado abstractamente como 'renta' por una legislación genere el impuesto correspondiente, es necesario que tenga algún tipo de conexión o vinculación con el país, esto es, que el Estado se atribuya jurisdicción en el sentido de potestad tributaria para hacer tributar ese fenómeno a sus arcas”. (p. 35).

En el ámbito fiscal internacional destacan los siguientes criterios:

a. Criterio personal o subjetivo: Este criterio hace referencia a la persona que obtiene la renta; según el cual, un Estado puede gravar a sus residentes por la renta global o mundial que obtengan.

b. Criterio de la fuente de la renta u objetivo: Señala que la renta debe ser gravada en el Estado en que se produce, el derecho a exigir un tributo se fundamenta en la "pertenencia" de la actividad o bien gravado, a la estructura económica de un determinado país. Afirma Romero Flor (2006) que vienen a ser “(...) los puntos 
de conexión el lugar donde se realiza la actividad, lugar donde se abona o el lugar donde reside el pagador" (pág. 224).

En nuestro país está gravada la totalidad de rentas obtenidas por los contribuyentes domiciliados en el Perú, aplicándose de forma conjunta el criterio personal y de la fuente. En tanto que, los contribuyentes no domiciliados en el Perú tributarán solo por sus rentas de fuente peruana. Ejemplo: la sucursal en el Perú de una empresa constituida en el extranjero. Asimismo, el artículo $9^{\circ}$ de la Ley del Impuesto a la Renta, ha previsto que el desarrollo de ciertas actividades genera rentas de fuente peruana, así como sus criterios de vinculación.

Actualmente, el criterio subjetivo o de residencia prevalece en la mayoría de los convenios para evitar la doble imposición, siguiendo el modelo OCDE, como afirma Villagra (2008):

"Lo cierto es que la perspectiva varía si se trata de países exportadores e importadores de capital; sin embargo, no existen legislaciones o Estados que unilateralmente renuncien a gravar en fuente, salvo la existencia de acuerdos o convenios bilaterales para evitar la doble imposición e incluso otro tipo de normas. Tal es el caso de la Directiva de la Unión Europea 2003/49/CEE sobre intereses y cánones entre empresas asociadas, en la cual ha primado el criterio de la residencia” (pág. 20).

\subsection{Límites discrecionales del "criterio de mínima conexión territorial”.}

Según Villagra (2008):

"Los límites discrecionales sobre los cuales se interpreta el criterio de mínima conexión territorial son amplios; no obstante, el ejercicio irrazonable de la jurisdicción tributaria sobre los no residentes podría ser impugnado como una violación del derecho internacional, tanto por el contribuyente, como por el Estado de la nacionalidad de éste.

La limitación más importante impuesta por el derecho internacional es el principio en virtud del cual un Estado no puede ejercer actividad administrativa alguna en territorio del otro Estado, salvo el permiso especial concedido por este último" (pág. 20).

Por ello, no está permitido que un Estado envié uno de sus funcionarios a otro Estado a fin de recoger información con fines tributarios, efectuar el cobro de tributos o verificar el contenido de las declaraciones juradas de un contribuyente. Desde hace algún tiempo, 
los Estados vienen suscribiendo acuerdos y tratados que permitan la asistencia mutua en el intercambio de información.

Nuestro país busca ingresar a la OCDE, siendo el motivo principal por el cual ha realizado modificaciones en la legislación tributaria. A través del Decreto Legislativo N¹315 publicado el 31 de diciembre de 2016, se incorporó en el Código Tributario el Titulo VIII sobre Asistencia Administrativa Mutua en Materia Tributaria.

\subsection{El problema de la doble imposición internacional}

El problema de la doble imposición se genera cuando dos o más Estados adoptan diferentes criterios de imposición. Romero Flor (2006) señala dos tipos de conflictos:

“(...) conflictos positivos, cada Estado va a definir, sin ninguna restricción, aquellos puntos de conexión por los cuales determinados hechos que graven una determinada renta o patrimonio, van a quedar sometidos a su normativa tributaria, sin tener en cuenta si aquellos hechos ya han sido (o van a ser) gravados por otro Estado. Sera en este tipo de conflictos positivos donde se producirá la doble imposición.

Por el contrario, los conflictos negativos se producirán cuando ninguno de los Estados con los que el hecho sometido a gravamen guarda conexión, se consideren competentes para someterlo a imposición”. (pág. 224).

Los conflictos positivos influyen en la decisión de los agentes económicos, que desean el mayor retorno de sus inversiones quienes a fin de evitar problemas de doble tributación internacional trasladan sus inversiones a Estados donde menos tributen.

\subsubsection{Concepto de doble imposición internacional}

Se entiende por doble imposición, al hecho de que una misma renta esté sujeta a dos o más tributos que sean similares, en general a dos impuestos y más concretamente, a dos impuestos sobre la renta. Puede producirse en el mismo país o como consecuencia de la colisión entre las normas de dos países distintos, en cuyo caso esa doble imposición pasa a llamarse doble imposición internacional.

En ese sentido, García Mullin (1980) afirma: “(...) el concepto de doble imposición internacional se integra con dos elementos: pluralidad de normas emanadas 
de diferentes entes con potestad tributaria, e identidad de hecho sometido a ellas" (p. 214).

Por ello, para la existencia de la doble tributación debe concurrir, como afirma (Romero Flor, 2006), "los siguientes elementos: un mismo sujeto pasivo, un mismo periodo de tiempo, concurrencia de impuestos de naturaleza idéntica o análoga y la existencia de varios sujetos activos" (pág. 217).

Un mismo sujeto pasivo, sobre quien recae el hecho imponible señalado en la normatividad de dos o más Estados. Cabe mencionar la importancia de distinguir el hecho de que exista una misma identidad subjetiva o la concurrencia de varias, para diferenciar figuras como la doble imposición económica o indirecta y la jurídica o directa.

Un mismo periodo de tiempo, se refiere a que la renta o patrimonio sometido a gravamen por legislaciones distintas debe haberse obtenido en un mismo periodo impositivo.

Con respecto al requisito de concurrencia de impuestos de naturaleza idéntica o análoga, Cosín Ochaita (como se citó en Romero Flor, 2006) estima que "la similitud de los impuestos debería realizarse mediante la comparabilidad de los elementos esenciales de los impuestos tales como hecho imponible, objeto imponible, base imponible, tipo impositivo y deducciones o bonificaciones en la cuota tributaria”. (pág. 221).

La concurrencia de varios sujetos activos, se refiere a que varios Estados gravan el mismo hecho imponible. Así, para Velásquez (2012) "los problemas que se presentan en un determinado Estado serán para establecer la renta de fuente extranjera de un residente y la renta de un no residente en ese Estado" (pág. 26).

A modo de ejemplo, podríamos decir que la doble imposición internacional generaría las siguientes consecuencias:

- Una excesiva carga fiscal sobre los contribuyentes. Supongamos que el día de hoy una empresa no domiciliada alemana presta un servicio dentro del territorio peruano a una empresa con domicilio fiscal en Perú, en ausencia de un CDI entre Alemania y Perú, dicho servicio se encontrará gravado localmente con una retención del 30\% por el impuesto a la renta generado, y del mismo modo, se verá sometido al pago de impuesto en Alemania. En tal sentido es lógico que dichos excesivos pagos de impuestos hagan inviable la operación comercial o, lo que es 
peor para la empresa peruana, que esta última se vea forzada contractualmente a asumir el pago del tributo (con la consiguiente imposibilidad de deducir el tributo asumido o vía incremento proporcional - "gross-up" de la contraprestación a pagar alno domiciliado).

- La doble imposición incrementa la elusión fiscal internacional en tanto que termina incentivando a los contribuyentes a optar por estructuras elaboradas para eludir el pago de impuestos.

\subsubsection{Modalidades de la doble imposición}

Dentro de la doble imposición, distinguimos dos categorías: la económica y la jurídica. La primera se produce por la incidencia del Poder Tributario sobre una misma renta o patrimonio por impuestos de carácter similar, pero en personas distintas. La doble imposición jurídica se da en aquellos casos en que se grava un mismo sujeto pasivo por una misma renta por impuestos similares.

\subsubsection{Doble imposición económica}

Esta figura se presenta cuando unas mismas rentas son gravadas a la vez por dos o más Estados, aunque en manos de sujetos "legalmente" distintos.

Esta figura puede surgir cuando se grava a las empresas por sus beneficios: primero por su obtención y luego cuando la sociedad reparte utilidades, la primera en cabeza de la empresa y, posteriormente, en cabeza del titular por los dividendos que recibe. Es la misma fuente de beneficio económico que origina imposición a dos sujetos distintos. En otras palabras, se gravan dos hipótesis fácticas distintas, pero que afecta a una sola fuente económica, la renta de la empresa o sociedad.

\subsubsection{Doble imposición jurídica}

Cuando un mismo sujeto es sometido a imposición sobre las mismas rentas por dos autoridades distintas. En otras palabras, que haya una identidad entre la persona que paga el impuesto en el extranjero y la persona que paga el impuesto en el Perú. 


\subsubsection{Mecanismos para evitar la doble imposición}

Uno de los principales problemas en temas de tributación internacional es el adecuado tratamiento de las rentas que se ven sometidas al poder tributario de dos o más países. Como señalan Rojas Novoa \& Baldeón Güere (2007):

Es así que, la aplicación de la soberanía fiscal frente a la generalización de operaciones internacionales de movimiento de capitales da lugar a la denominada doble imposición. La doble o múltiple tributación se presenta cuando dos o más Estados consideran que les pertenece el derecho de gravar una determinada renta. En ese sentido, una misma ganancia podría resultar gravada por más de un Estado (págs. I-1).

La principal causa de la doble imposición es la adopción de los países de diferentes criterios de vinculación, los cuales fueron señalados anteriormente. A fin de atender estos conflictos, los Estados consideran soluciones unilaterales o soluciones pactadas (por la que dos o más Estados trataran de común acuerdo hacer frente a la doble imposición internacional).

\subsubsection{Soluciones Unilaterales.}

Las medidas unilaterales son dispuestas por los Estados de forma independiente en su normativa fiscal interna, buscando con ello evitar o limitar la doble imposición generada. Dentro de las medidas unilaterales podemos mencionar las señaladas por Rojas Novoa \& Baldeón Güere (2007):

- Reglas de residencia: se establece en la legislación reglas por las cuales se considera residente a un sujeto en virtud de una lista de criterios a efectos de considerar dentro de la soberanía fiscal de un Estado la renta que produce dicho residente.

- Reglas de transparencia fiscal internacional: en aplicación de dicha regla, al verificarse las condiciones que hacen suponer que la creación de sociedades en determinados lugares ha sido para reducir los impuestos, se hace tributar al contribuyente residente que se encuentra detrás de dicha sociedad, sin tener en cuenta de si se han distribuido beneficios o no. Las reglas de transparencia fiscal se aplican para el caso de rentas pasivas, es decir, rentas que no provienen de 
actividad empresarial, son rentas que provienen de activos; por ejemplo, valores mobiliarios.

- Reglas sobre fondos de inversión extranjera: muchas veces se ha pretendido burlar las reglas de transparencia fiscal internacional mediante la creación de un fondo de inversión; toda vez que estos últimos, por su propia naturaleza, pertenezcan a un gran número de partícipes, no siendo posible en tal circunstancia aplicar las reglas de transparencia fiscal en la que se hace tributar al contribuyente residente que está detrás de la sociedad. Para ello, se establecen las reglas sobre fondos mutuos de inversión, estableciéndose que los partícipes imputarán a sus bases, el aumento de valor de su participación al final del período imponible.

- Reglas sobre precios de transferencia: son reglas que permiten evitar que mediante una valoración distorsionada se transfieran bases imponibles entre empresas vinculadas, para lo cual se establecen reglas para que las operaciones entre vinculadas, sin alterar los precios de los bienes ni de los servicios.

- Retenciones en la fuente discriminatorias: en aplicación de esta regla, se establece que están sujetos a retención los pagos que se efectúan a residentes en paraísos fiscales.

- Restricción de la deducción de gastos pos pagos realizados en paraísos fiscales: en aplicación de esta regla, se niega la deducibilidad de gastos realizados en países de nula imposición (págs. I-2).

Por ejemplo, de acuerdo a nuestra legislación interna, en el Perú se utiliza como mecanismo unilateral para evitar situaciones de doble imposición, el sistema del crédito, por el cual permite a sus residentes aplicar contra el Impuesto a la Renta local aquellos impuestos pagados en el exterior sobre las mismas rentas gravadas en nuestro país.

\subsubsection{Soluciones Bilaterales.}

Al adoptarse soluciones bilaterales, dos Estados establecen acuerdos para evitar discrepancias entre sus legislaciones respecto a la materia tributaria. Con la suscripción de un Convenio de Doble Imposición, las partes adquieren una obligación de Derecho Internacional (CDI). 
En los CDI, los dos estados contratantes se comprometen a restringir o renunciar a su potestad tributaria, obligándose a no establecer ningún tributo con respecto a la potestad otorgada al otro Estado; aunque pueden surgir problemas de doble no imposición.

Cabe destacar, que estos acuerdos no describen el sistema tributario de cada país, ni la tasa del impuesto a la renta a aplicar frente a una determinada operación.

Los CDI son instrumentos en virtud de los cuales los Estados contratantes fijan límites y parámetros para que cada uno de ellos aplique su legislación interna, considerando las disposiciones del tratado. A pesar de que se trata de acuerdos entre Estados, los CDI tienen efectos directos en los contribuyentes, quienes pueden invocar la aplicación de sus disposiciones y beneficios respectivos

Chiarella Privette (2010) afirma:

"Si bien el objetivo inmediato del CDI es evitar la doble imposición, su finalidad principal es la de permitir el libre flujo de inversiones, personas, bienes y servicios entre los Estados contratantes.

Un punto fundamental con respecto a los CDI, es que estos acuerdos no crean derechos a favor de los Estados contratantes de someter a imposición rentas que no están gravadas según su legislación interna. Un Estado no puede basar su jurisdicción tributaria en el hecho de que bajo el CDI de que se trate "puede" someter a imposición determinada renta”. (pág. 127).

Conforme a algunas reglas de los CDI, ciertas rentas o patrimonio pueden ser gravados únicamente en uno de los dos Estados; y, otras rentas o patrimonio, pueden ser gravados en los dos Estados de forma proporcional, limitando la potestad del Estado de la fuente a un porcentaje especifico. Por ejemplo: Según el artículo $12^{\circ}$ primer párrafo del Modelo OCDE, las regalías solo pueden ser gravadas en el Estado de residencia. El Estado de la fuente carece de potestad tributaria. Sin embargo, los dividendos si pueden ser gravados en el Estado de la fuente, conforme al artículo $10^{\circ}$ segundo párrafo del Modelo OCDE. Dependiendo del porcentaje de participación del beneficiario efectivo, el Estado de la fuente puede gravar los dividendos al 5 o al $15 \%$ de su importe bruto. El Estado de residencia también los gravará, pero otorgará un crédito por los impuestos pagados en el otro Estado. 


\subsubsection{Soluciones Multilaterales.}

Al respecto Rojas Novoa \& Baldeón Güere (2007) señala lo siguiente:

"En mérito a ello diversos países normalmente de una misma área geográfica o de un nivel de desarrollo similar deciden la adopción de principios o realizan reformas dentro de sus legislaciones con la finalidad de solucionar problemas que a todos los afecta. Ejemplo: el código de conducta sobre fiscalidad de las empresas de la Unión Europea" (págs. I-2).

\subsubsection{Métodos para eliminar la doble imposición.}

Para Rojas Novoa \& Baldeón Güere (2007):

"Los métodos de que se sirven los estados para resolver el problema de la doble imposición se dirigen básicamente a eliminar o atenuar la doble imposición que es consecuencia del enfrentamiento de los principios de territorialidad en el Estado de la fuente y de personalidad en el Estado de residencia" (págs. I-3).

El Modelo de Convenio Tributario sobre la Renta y sobre el Patrimonio, en los artículos 23A y 23B, deja a elección de los Estados contratantes dos métodos para evitar la doble imposición: método de exención y el método de imputación, ambos con sus respectivas variantes.

Aunque los Estados gozan de plena libertad a la hora de elegir el método a aplicar cuando surge la doble imposición, la inmensa mayoría de ellos, se basan en el Modelo de Convenio de la OCDE (Comité Fiscal de la Organización para la Cooperación y Desarrollo Económico), el cual limita el número de métodos utilizables basados en cada principio directivo, permitiéndose a los países Miembros optar por el método de exención con progresividad y el método de imputación ordinaria.

\subsubsection{Método de exención o reparto.}

Por este método, el Estado de residencia no grava las rentas imponibles originadas en el Estado de la fuente. Por ello, este método es también conocido con el nombre del sistema de reparto en cuanto que implica una distribución del gravamen entre el estado de la residencia y el estado de la fuente al limitar el primero, a través de la exención, la extensión de su soberanía tributaria. 
Este método admite dos modalidades:

a. La exención íntegra, por el cual la renta percibida en el Estado de fuente no es tomada en cuenta de ninguna forma por el Estado de la residencia para efectos impositivos.

b. La exención con progresividad, por la cual el Estado de residencia renuncia al gravamen de las rentas originadas en el extranjero, pero conserva el derecho a tomar en cuenta esta renta a fin de determinar el tipo progresivo que corresponde aplicar a las restantes rentas no excluidas.

El método de exención (tanto integral como con progresividad), al actuar sobre la base del impuesto, va a ser defendido por los países importadores de capital (países en vías de desarrollo) que no verán contrarrestados en el país de residencia los incentivos fiscales que aquellos ofrecen para atraer inversiones extranjeras.

\subsubsection{Método de imputación.}

Según Bassallo (2008):

"Por este método el Estado de residencia calcula el impuesto basándose en el importe total de las rentas del contribuyente, incluyendo las que provienen del Estado de la fuente, qué con arreglo del acuerdo entre ambos Estados, pueden someterse a imposición en ese otro Estado, (pero sin incluir las rentas que pueden someterse a imposición sólo en el Estado de la fuente). El Estado de residencia deduce del impuesto que se le adeuda el impuesto que ha sido soportado en el Estado de la fuente. En consecuencia, consiste en la concesión de un crédito fiscal por el impuesto pagado en el extranjero" (pág. 394).

Para que este método pueda ser aplicado, es necesario que los impuestos de ambos países sean de naturaleza idéntica o análoga y que, además, la cantidad que el sujeto pasivo pretenda deducir, haya sido efectivamente pagada en el país de la fuente.

Este método tiene dos modalidades:

a. Imputación Íntegra, por la cual el país de residencia admite la deducción íntegra del Impuesto pagado en el país de la fuente

b. Imputación Limitada u Ordinaria. En la que el Estado de residencia deduce el impuesto previamente satisfecho, pero hasta el límite máximo de lo que correspondería pagar si la renta se hubiera obtenido en dicho Estado. Siendo que 
la deducción del impuesto extranjero está limitada a la cantidad resultante de aplicar la tasa vigente de gravamen del Estado de residencia a las rentas obtenidas en el otro Estado.

Es decir, el Estado de residencia permitirá la deducción de la menor de las siguientes cantidades (de aquí la denominación de "limitada”):

- El impuesto efectivamente satisfecho en el país de la fuente;

- Cantidad resultante de aplicar el tipo de gravamen del Estado de residencia a la renta obtenida en el país de origen, por lo que se considerará tal renta, como si se hubiera obtenido en el país de residencia.

Romero Flor (2006) afirma:

"El método de imputación, al actuar sobre el propio impuesto a través de la cuota, va a ser defendido por los países industrializados (exportadores de capital), entre otras razones, porque verán incrementados sus ingresos tributarios, consiguiéndose, además anular el interés de invertir en países distintos al de la residencia del inversor.

Esta última razón ha sido la que mayores críticas ha recibido el método de imputación por parte de los países en vías de desarrollo, que ven como los países que aplican este mecanismo absorben para sí los incentivos que conceden a los sujetos pasivos para invertir en sus países, es decir, los beneficios tributarios (exenciones o bonificaciones) otorgadas al sujeto pasivo por el país de la fuente, tributarán en el país de la residencia (aun no habiendo tributado en el país de la fuente)" (pág. 239).

\subsubsection{Método para evitar la doble imposición en la Legislación Interna.}

Bassallo Ramos (s.f.) afirma que "Los métodos para evitar la doble imposición a nivel bilateral o multilateral, coexisten con los mecanismos unilaterales, los mismos que están recogidos en la legislación peruana del Impuesto a la Renta” (pág. 397). El método unilateral sobre la aplicación del impuesto a la renta pagado en el exterior a manera de un crédito está regulado en el inciso e) del artículo $88^{\circ}$ de la LIR.

\subsubsection{Aplicación del crédito pagado en el exterior según la Ley del Impuesto a la Renta.}

El inciso e) del artículo $88^{\circ}$ de la Ley del Impuesto a la Renta establece lo siguiente: 
Los contribuyentes, obligados o no a presentar las declaraciones a las que se refiere el artículo $79^{\circ}$ de la Ley, deducirán de su impuesto los conceptos siguientes:

\section{$(\ldots)$}

e) Los impuestos a la renta abonados en el exterior por las rentas de fuente extranjera gravadas por esta Ley, siempre que no excedan del importe que resulte de aplicar la tasa media del contribuyente a las rentas obtenidas en el extranjero, ni el impuesto efectivamente pagado en el exterior. El importe que por cualquier circunstancia no se utilice en el ejercicio gravable, no podrá compensarse en otros ejercicios ni dará derecho a devolución alguna.

Coincidimos con Bassallo Ramos (s.f.), respecto a la normativa en mención al afirmar que:

“(...) se establece una limitación temporal para la utilización como crédito del impuesto pagado en el Estado de la fuente, ya que si no es utilizado dicho crédito durante el ejercicio de su generación, no sería posible arrastrar el mismo en ejercicios siguientes, ni sería posible su devolución, por lo que en dicho contexto el crédito se perdería en forma irreparable" (pág. 394).

De la lectura de las disposiciones contenidas en el inciso e) del artículo $88^{\circ}$ de la LIR, no regulan específicamente este aspecto. Sin embargo; como manifiesta Cores Ferradas (2010) respecto al artículo en cuestión:

“(...) señala que los importes no utilizados en el ejercicio gravable no son compensables en otros ejercicios, podría interpretarse que ante la situación anteriormente descrita el contribuyente no tendría derecho al crédito (...) Lo cual es cuestionable, toda vez que se perjudicaría al contribuyente por una situación no causada por el propio obligado, sino por las diferencias en los momentos que deben reconocerse los ingresos y los momentos en los que deben efectuarse las retenciones". (pág. 114) 


\section{CAPÍTULO II: TRATAMIENTO DEL CRÉDITO EN EL PERÚ Y EN LA LEGISLACIÓN COMPARADA}

\subsection{Tratamiento del crédito}

En la actualidad, cada país adopta o emplea diversos medios para aliviar o eliminar situaciones de doble imposición, aplicando así mecanismos multilaterales, bilaterales y/o unilaterales, como ya se ha expuesto en el capítulo anterior.

Centrémonos específicamente en los métodos unilaterales (aquellos aplicados por un país según su legislación interna), que como ya se ha dicho, son dos típicamente utilizados contra la doble imposición: (i) el primero es el método "territorial" o de “exención”, bajo el cual el país de residencia no grava las rentas de fuente extranjera, y cede jurisdicción al país de la fuente. En su acepción más pura, un Estado que aplica este método se limita a gravar únicamente las rentas generadas en su territorio (rentas "nacionales"); (ii) el segundo método es de "imputación" o "crédito", en el cual el país de residencia grava también la renta de fuente extranjera pero permite utilizar como crédito el impuesto pagado en el exterior.

El crédito por impuestos pagados en el exterior, en términos sencillos, como afirma Plazas Vega (2008), “consiste en que el país exportador de la inversión concede al contribuyente un descuento equivalente a los impuestos que pague en el exterior con motivo de la realización de rentas fuera del país" (pág. 423).

El Perú utiliza como mecanismo unilateral para evitar situaciones de doble imposición, el sistema del crédito, el cual permite a sus residentes aplicar contra el Impuesto a la Renta local aquellos impuestos pagados en el exterior sobre las rentas de fuente extranjera gravadas en nuestro país.

Flores Benavides afirma que:

“(...) cuando el descuento se refiere a los impuestos soportados en el exterior por el mismo sujeto que aplica el crédito en el país de la residencia (por ejemplo, una empresa local brinda servicios a un cliente extranjero y la retribución está sujeta a retenciones impositivas en el país de este último), entonces estamos ante el llamado crédito directo. Podemos advertir del ejemplo que el mecanismo del crédito directo básicamente permite paliar la doble imposición jurídica. A su vez, si el crédito tributario se compone de los 
impuestos pagados por un sujeto técnicamente distinto al que lo aplica, aunque en un sentido más amplio, referidos a unas mismas rentas (el típico problema de las utilidades gravadas cuando son generadas en el país de la fuente, y luego nuevamente cuando son recibidas vía dividendos en el país de la residencia), el mismo se denominará crédito indirecto" (pág. 463).

Como vemos, el crédito indirecto es útil para combatir la doble imposición económica (también llamada “doble imposición intersocietaria internacional”).

Conviene señalar en este punto que, virtualmente, ningún país en el mundo ofrece de manera exclusiva solo uno de los dos métodos explicados (exención o crédito), sino más bien, una combinación de ambos. Así lo explican con claridad Blanluet y Durand: “De hecho, ningún país opera un sistema de crédito puro o un sistema de exención puro.

El método del crédito se abre paso en los sistemas de tributación territorial, como lo hace el método de exención en los sistemas de tributación mundial. Por tanto, más allá de distinciones conceptuales entre tributación mundial y tributación territorial, todos los sistemas tributarios aplicables tienen un carácter híbrido, lo que significa que combinan los sistemas de exención y crédito, y esto dependerá de varios factores, como la naturaleza o fuente de la renta o de si se puede aplicar algún convenio tributario.

\subsubsection{El crédito tributario indirecto en el Perú}

El inciso e) del artículo $88^{\circ}$ de la Ley del Impuesto a la Renta dispone que los contribuyentes domiciliados en Perú puedan aplicar como crédito contra su impuesto anual, lo siguiente:

e) Los impuestos a la renta abonados en el exterior por las rentas de fuente extranjera gravadas por esta Ley, siempre que no excedan del importe que resulte de aplicar la tasa media del contribuyente a las rentas obtenidas en el extranjero, ni el impuesto efectivamente pagado en el exterior. El importe que por cualquier circunstancia no se utilice en el ejercicio gravable, no podrá compensarse en otros ejercicios ni dará derecho a devolución alguna.

Esta norma ha sido reglamentada por el art. $52^{\circ}$ del reglamento de la LIR, que regula la tasa media al señalar:

$(\ldots)$ 
d) Para efecto de lo dispuesto en el inciso e) del artículo $88^{\circ}$ de la Ley, por tasa media se entenderá el porcentaje que resulte de relacionar el impuesto determinado con la renta neta global o con la renta neta de tercera categoría, según fuera el caso, sin tener en cuenta la deducción que autoriza el artículo $46^{\circ}$ de la misma. De existir pérdidas de ejercicio anteriores éstas no se restarán de la renta neta.

Cuando conjuntamente con la renta neta global el contribuyente tuviera rentas de tercera categoría, para el cálculo de la tasa media se considerará la renta neta que corresponda a la actividad de donde provenga la renta de fuente extranjera.

Adicionalmente, el art. $58^{\circ}$ del mismo Reglamento plantea algunas cuestiones a tener en cuenta para efectos del crédito por Impuesto a la Renta abonado en el exterior. El artículo señala:

Para efecto del crédito por Impuesto a la Renta abonado en el exterior, a que se refiere el inciso e) del artículo $88^{\circ}$ de la Ley, se tendrá en cuenta lo siguiente:

1. El crédito se concederá por todo impuesto abonado en el exterior que incida sobre rentas consideradas como gravadas por la Ley;

2. Los impuestos pagados en el extranjero, cualquiera fuese su denominación, deben reunir las características propias de la imposición a la renta; y,

3. El crédito sólo procederá cuando se acredite el pago del Impuesto a la Renta en el extranjero con documento fehaciente.

A fin de utilizar el impuesto pagado en el Estado de la fuente, se pueden aplicar las siguientes reglas:

a. Esos impuestos deben haber incidido sobre rentas calificadas por nuestra legislación como provenientes de "fuente extranjera".

Esta condición es internacionalmente aceptada, toda vez que lo contrario permitiría que el impuesto que grava rentas consideradas como de fuente peruana, sea cobrado por otra jurisdicción. Más aún, los países renuncian únicamente a la potestad de establecer impuestos sobre rentas que tienen su origen en su jurisdicción a través de convenios u otros acuerdos.

La regla general es que los servicios son de fuente peruana cuando son prestados en el territorio peruano. Sin embargo; tenemos casos especiales que se rigen por otros criterios de vinculación como son los servicios de asistencia 
técnica (criterio de utilización económica) y servicios digitales (utilización económica, uso o consumo en el país).

¿Qué sucede cuando una sociedad peruana brinda fuera del territorio nacional servicios de asistencia técnica a una compañía extranjera con relación a inversiones en el Perú? Los beneficios calificarían como rentas de fuente peruana, pero también estarían gravadas al mismo tiempo con el impuesto a la renta en el Estado donde desarrollo sus actividades por el criterio de la fuente. La empresa peruana no podría deducir como crédito el impuesto pagado en el exterior, porque tal posibilidad solo se admite respecto de tributos pagados por rentas de fuente extranjera; sin embargo, podría deducirlo como gasto por renta de fuente peruana.

\section{b. Estas rentas deben ser consideradas como gravadas por nuestra ley.}

c. Los impuestos pagados en el exterior deben reunir las características propias de la imposición a la renta.

$\mathrm{Al}$ respecto Cores Ferradas señala que:

“(...) debe tenerse presente que una de las características principales de la imposición sobre la renta, es que debe aplicarse sobre la denominada renta neta. En relación a este requerimiento John P. Steines Jr. (2004) sostiene que “(...) la imposición sobre renta neta debe reunir tres condiciones: el impuesto debe aplicarse sobre transacciones que conlleven la realización de una renta; la renta gravada debe iniciarse como una renta bruta y debe tener una deducción de los costos significantes".

En este contexto, es importante resaltar que en muchos casos los impuestos a la renta abonados en el extranjero no cumplen con este requisito, toda vez que generalmente son determinados como retención sobre renta bruta; esto es, sin deducción alguna. Sin embargo, ha sido una práctica aceptada en el país que los impuestos determinados sobre renta bruta sean permitidos como crédito contra el Impuesto a la Renta en el Perú” (pág. 75).

d. Debe acreditarse el pago del impuesto en el extranjero con documento fehaciente. 
Este requisito exige a los contribuyentes acreditar en pago efectivo en el extranjero. Si bien pareciera no admitir mayor dificultad tal requisito, genera una serie de interrogantes respecto al ejercicio en el cual debe efectuarse el pago del impuesto.

Cabe preguntarse qué sucede cuando la liquidación del tributo en el exterior no coincide con el ejercicio en que el contribuyente domiciliado reconoce la renta.

En la medida que el inciso e) del artículo $88^{\circ}$ de la Ley del Impuesto a la Renta señala que los importes no utilizados en el ejercicio gravable no son compensables en otros ejercicios, es necesario que se precise el alcance de este requisito para no perjudicar al contribuyente, por una situación ajena, ya que dependerá del fisco extranjero fijar la oportunidad de pago del impuesto. Por ello coincidimos con Roberto Cores (2010), en que se establezca que el crédito por IR pagado en el exterior debe emplearse en el mismo ejercicio en que se reconoce la renta, siempre que sea pagado conforme a la legislación extranjera dentro del plazo para presentar la declaración jurada en el Perú.

e. El crédito a ser usado tiene dos límites: la tasa media del contribuyente peruano y el monto efectivamente pagado en el exterior.

f. La forma de calcular la tasa media del contribuyente y por tanto el límite del crédito, variará dependiendo si estamos ante una empresa o un sujeto sin negocio.

Tal como se señalaba en la parte introductoria del presente trabajo materia de investigación, el crédito por el impuesto pagado en el exterior que regula la ley peruana no es otro que el crédito directo. Es decir, el legislador no ha tomado en cuenta el reconocimiento del crédito tributario indirecto como medida unilateral para aliviar los problemas de doble imposición económica que puedan surgir. 
Con la crítica que desarrollamos, no se pretende minimizar la tarea difícil que implicaría estructurar normas adecuadas que regulen la correcta aplicación del crédito indirecto en nuestra legislación.

A decir verdad, es reconocido que el tratamiento complejo del crédito indirecto ha hecho que países que se rigen por el Sistema del Crédito, como es el caso de Finlandia, Suecia, Corea del Sur, Argentina y el Perú, reconozcan en su legislación interna solo la aplicación del crédito directo y el otorgamiento del crédito indirecto siempre que sea por medio de un tratado internacional.

No sólo debemos analizar los riesgos y ver la complejidad, sino también ver los beneficios que traería una mayor inversión en el exterior; por ejemplo, un país que está considerando incorporar el mecanismo del crédito indirecto puede evitar algunas de las mayores complejidades que surgen de la aplicación del mismo, si permite que el crédito indirecto se utilice solo si la filial extranjera distribuye sus utilidades como dividendo en el año en que son generadas. De esta manera, se estaría enfrentando uno de los mayores obstáculos que enfrenta la aplicación del crédito indirecto que se origina cuando los contribuyentes reclaman créditos por impuestos extranjeros pagados por sus filiales extranjeras de las ganancias acumuladas durante años. Es por ello que si se aplican restricciones se puede resolver en gran parte dicho obstáculo.

Otra consecuencia de no permitir la utilización del crédito indirecto, es que tal situación origina un alto costo impositivo en aquellas jurisdicciones en las cuales se establece solamente un nivel de imposición y, por ende, en las cuales la distribución de dividendos no se encuentra sometida a imposición. Cores Ferradas afirma que:

"En efecto, en tal supuesto el impuesto pagado en el país de fuente no podrá ser utilizado en el Perú por la empresa receptora de los dividendos, toda vez que se trata de un impuesto pagado por una entidad diferente. A su vez, los dividendos obtenidos por la empresa peruana se encontrarán sometidos a imposición como rentas de fuente extranjera, sin tener derecho a aplicar crédito alguno" (pág. 76).

Sin embargo, el escenario económico actual justifica con creces el esfuerzo de diseñar una fórmula legal que recoja el crédito indirecto, pues como ha sostenido la doctrina nacional al discutir sobre las inversiones peruanas en el exterior, el reconocer únicamente el crédito directo derivado de impuestos a la renta abonados en el exterior por rentas de fuente extranjera, y no así la deducción de los créditos indirectos o "impuestos subyacentes", ocasiona una doble imposición económica a nivel internacional. 
Tal como lo señala Córdova Arce (2010):

“(...) urge incorporar en la legislación interna la figura del crédito indirecto por los impuestos a la renta abonados por las sociedades, filiales o entes autónomos residentes en el extranjero, en sus distintos niveles, a fin de eliminar o mitigar el fenómeno de doble o múltiple imposición económica y facilitar la repatriación de dividendos obtenidos en el exterior” (pág. 84).

Entonces, estaría claro que nuestra norma debe incorporar el crédito indirecto no sólo porque ello aliviaría la doble imposición económica, como hacen referencia Liu Arévalo \& Vargas León (2006), afirmando:

“(...) que corregiría una distorsión que se da al no existir la figura. Sin perjuicio de las ventajas tributarias que puede traer operar en el extranjero mediante una subsidiaria, está demostrado en el Derecho comparado que la inexistencia del "crédito indirecto" discrimina a favor del sujeto que opera en el exterior mediante una sucursal (que para estos efectos equivale a operar directamente), frente al que lo hace mediante una subsidiaria” (pág. 305).

\subsubsection{Posibilidad de deducir como gasto los impuestos pagados en el exterior que no pueden ser utilizados como crédito}

Nuestra normativa no establece la posibilidad de deducir como gasto la parte del impuesto pagado en el extranjero que excede el monto que puede ser acreditado contra el impuesto a la renta, tampoco hace referencia a aquellos impuestos pagados en el extranjero respecto de rentas calificadas por la LIR como rentas de fuente peruana.

En efecto, el inciso e) del artículo $88^{\circ}$ de la LIR impide la utilización del crédito en ejercicios futuros, así como su devolución. En tal sentido, y al tratarse de una erogación necesaria para la obtención de la renta gravada de fuente extranjera, consideramos que existirían argumentos para sustentar su deducción al amparo de lo dispuesto por el artículo $51^{\circ}$-A de la LIR.

Asimismo, el Informe 023-2015/SUNAT (2015), señala que "si bien no constituye crédito el impuesto pagado en el país de fuente con posterioridad a la presentación de la declaración jurada anual en el Perú, sí constituye gasto deducible para la determinación de la renta neta de fuente extranjera de la empresa domiciliada en el Perú”. 


\subsubsection{Análisis del Informe emitido por el MEF, $N^{\circ}$ 147-2014-EF/61.01}

El 05 de mayo del 2014 se emite el informe $\mathrm{N}^{\circ}$ 147-2014-EF/61.01, elaborado por la Dirección General de Política de Ingresos Públicos del Ministerio de Economía y Finanzas $^{1}$, en opinión al Proyecto de Ley $N^{\circ} 3599 / 2013-C R$, que incorpora el inciso f) al artículo $88^{\circ}$ de la Ley del Impuesto a la Renta, referido al crédito indirecto.

El informe señala que la doble imposición económica no es resultado de que el Perú no admita como crédito el impuesto sobre la renta pagado por un no domiciliado en el extranjero por las rentas empresariales con cargo a las cuales paga los dividendos, sino que aquella es una problemática que surge por el reconocimiento de las subsidiarias, como entes independientes a la casa matriz por parte de los diferentes países, quienes al ejercer su potestad tributaria gravan los beneficios empresariales o similares en cabeza de ellas. (Citado por George Kofler, 2012, pág.77).

Asimismo, se especifica que la incorporación del crédito indirecto en la Ley del Impuesto a la Renta ocasionaría una disminución en la recaudación del impuesto debido a que permitiría a los contribuyentes acreditar como crédito un impuesto pagado en una jurisdicción distinta, que incluso podría tener una tasa impositiva superior a la del Perú².

De esta manera, podría ser utilizado como una herramienta de planificación fiscal entre la casa matriz y las subsidiarias para reducir el pago del impuesto en el Perú, al colocar sus inversiones para generar sus rentas empresariales (con cargo a las cuales distribuye dividendos) en terceros países con los cuales el Perú no tenga Convenios para evitar doble imposición o Acuerdo de Intercambio de Información y por lo tanto la Administración Tributaria no puede acceder a la información detallada de dichos contribuyentes.

De lo expuesto, si bien es cierto el informe presentado por la Dirección General considera que no es procedente la propuesta de incorporar el método del crédito indirecto en la Ley del Impuesto a la Renta, se debe tener en cuenta que, el crecimiento de las inversiones de empresas peruanas en el exterior y su desarrollo en los mercados internacionales es innegable; en consecuencia, nuestra legislación interna debería contar

\footnotetext{
${ }^{1}$ A lo largo del año 2014 se discutieron y aprobaron una serie de leyes destinadas a promover la inversión, el crecimiento y la reactivación de la economía.

${ }^{2}$ A diferencia del crédito directo regulado en el inciso e) del artículo $88^{\circ}$ de la Ley del Impuesto a la Renta que limita la deducción del impuesto pagado en el exterior, a la tasa media del contribuyente por sus rentas obtenidas en el extranjero y al impuesto efectivamente pagado en el exterior.
} 
con un mecanismo que permita facilitar la repatriación de dividendos obtenidos en el exterior y mitigar o eliminar la doble imposición económica.

Claro está que, para adoptar un mecanismo como el de la aplicación del crédito indirecto se tendrían que cumplir con ciertos requisitos que le permitan al ente recaudador ejercer sus facultades de fiscalización y determinación de manera óptima y, además, le permitan llevar un control sobre este tipo de operaciones y que se traten de impuestos análogos verdaderamente pagados en el exterior.

En este punto, estamos de acuerdo en que no aceptar la deducción del crédito indirecto afecta la competitividad de las empresas peruanas que buscan invertir en el exterior, empujándolas a emplear sociedades intermedias, con los costos que ello implica, pues en cualquier caso deben tener sustancia y ser reflejo de operaciones reales. Tenemos el siguiente ejemplo: Colombia es un país que incorporó en su régimen tributario el sistema de crédito indirecto, a fin de utilizar el Convenio para Evitar la Doble Imposición entre los países miembros de la Comunidad Andina.

Figura 2.1.

Tratamiento del Crédito Indirecto en Colombia.
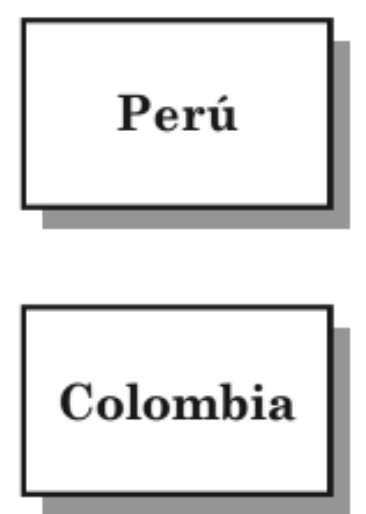

Argentina

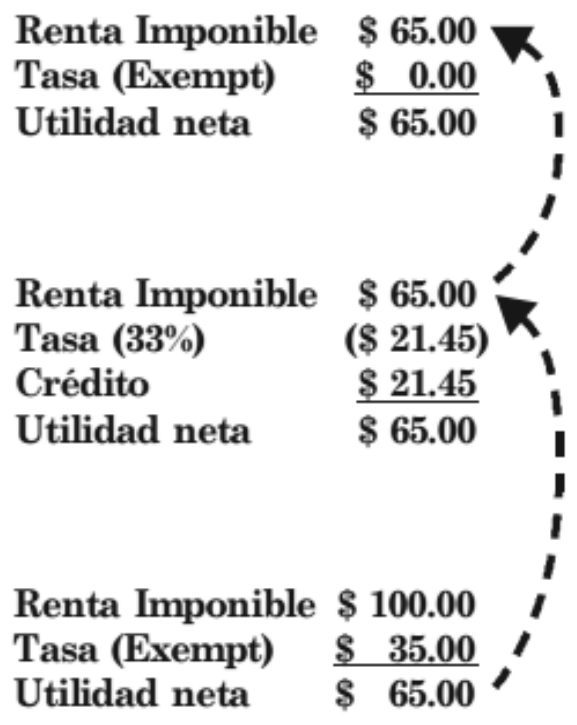


Lo adecuado sería que nuestro país cuente con las herramientas para evitar la doble imposición internacional, permitiendo que los rendimientos de las inversiones en el exterior retornen al Perú y alimenten con ello la economía del país.

La figura planteada presenta la debilidad de que al calificar los dividendos como exonerados conforme al Convenio para Evitar la Doble Imposición entre los países de la Comunidad Andina, los gastos y costos asociados podrían ser objeto de limitación en su deducción, con el perjuicio que ello involucra en términos de competitividad. (Citado en Ramón Gálvez Márquez, 2010, pp. 255 - 271).

A manera de conclusión, no estamos de acuerdo con el informe del MEF, puesto que extender y promover la aplicación del crédito indirecto tendría un impacto positivo en el incremento de las inversiones peruanas en el exterior, y el crecimiento económico del país.

\subsubsection{Inversiones en el extranjero - Sucursales vs. Subsidiarias: Aplicación del crédito}

Si bien nuestro país es considerado como un importador de capital extranjero, hay empresas nacionales que buscan exportar capital y deben evaluar la forma de inversión que les permita un mayor rendimiento económico. Por ello, la importancia fiscal al momento de decidir si invertir mediante una subsidiaria o una sucursal. De la revisión de la Ley del impuesto a la Renta se puede apreciar un tratamiento poco favorable para aquellos que decidan invertir en el exterior a través de una subsidiaria, según se podrá apreciar en el siguiente cuadro comparativo:

Tabla 2.1.

Diferencias de invertir entre una sucursal y una subsidiaria 
impuesto pagado en el extranjero por la sucursal.

Las pérdidas de la sucursal no son compensables por prohibición de la ley.

No se pueden diferir las rentas de la sucursal, automáticamente se atribuyen al ser una misma entidad.

Se excluyen las reglas del Régimen de Transparencia Fiscal Internacional. aplicar como crédito el impuesto a la renta corporativo.

Las pérdidas no son compensables por corresponder a un tercero.

Las rentas van a tributar cuando se perciban.

Excepción de tributar cuando se perciba, cuando sea aplicable el Régimen de Transparencia Fiscal Internacional.

\section{a) Sucursal:}

En la pagina web de la Revista Asesor Empresarial (2010) señalan que:

"Las sucursales son entidades que no conllevan la creación de una persona jurídica distinta a la matriz, y son la consecuencia de la dispersión de establecimientos de una misma sociedad que mantiene su unidad jurídica con la sociedad que la generó, aun cuando desempeñan la mayor parte de las funciones de una empresa independiente, estando solo bajo inspección y control de la casa central respecto de los recursos y obligaciones de cada periodo".

La Administración Tributaria, de acuerdo a lo señalado en el Informe N. ${ }^{\circ}$ 023-2015SUNAT (2015), afirma:

“(...) una sucursal, agencia u otro tipo de establecimiento permanente en el exterior establecido por una persona jurídica domiciliada en el país es parte de esta -careciendo consecuentemente de personalidad jurídica propia-, no habiendo la LIR dispuesto que aquellos se consideren, para sus efectos, personas jurídicas y, por ende, contribuyentes de tal impuesto".

Un contribuyente domiciliado en el país se encuentra obligado a pagar el impuesto a la renta por sus rentas de fuente mundial; es decir, por sus ingresos que califican como rentas de fuente peruana y aquellas que califican como rentas de fuente extranjera obtenidas por sus sucursales o establecimientos permanentes por actividades en el extranjero. 
La LIR permite que solo en el caso de las sucursales se pueda aplicar un "crédito directo". El reglamento del IR, establece que el crédito se concederá por todo impuesto abonado en el exterior que incida sobre las rentas consideradas como gravadas en el Perú. Los impuestos pagados en el extranjero, cualquiera fuese su denominación, deben reunir las características propias de la imposición sobre la renta y, el crédito sólo procede cuando se acredite el pago del IR en el extranjero con documento fehaciente.

$\mathrm{Al}$ respecto, en el Informe $\mathrm{N}^{\circ}$ 024-2017-SUNAT/5D000 (2017), la Administración Tributaria señala:

"En el supuesto de una empresa domiciliada en el Perú que tiene una sucursal en otro país, a través de la cual obtiene utilidades que son enviadas al Perú, que constituyen para aquella rentas de fuente extranjera gravadas con el impuesto a la renta en este país; y que son objeto de retención del impuesto a la renta en el país donde se ha establecido dicha sucursal; el impuesto así retenido en el exterior con ocasión del reparto o distribución de las utilidades a la empresa domiciliada en el Perú a la que pertenece dicha sucursal, constituye crédito contra el impuesto a la renta que determine aquella empresa en el Perú; estando sujeto a los límites y condiciones para su procedencia señalados en el inciso e) del artículo $88^{\circ}$ de la LIR y en el artículo $58^{\circ}$ del Reglamento".

Cabe mencionar que, el impuesto retenido en el exterior, podrá ser utilizado como crédito contra el Impuesto a la Renta Peruano en el ejercicio en que se reconoce tal renta en el Perú; por ello, si fue pagado con posterioridad al vencimiento del plazo para presentar la declaración jurada anual del Impuesto a la Renta (peruano) por el ejercicio correspondiente, no podrá compensarse en ese ejercicio ni en otros ejercicios ni dará derecho a devolución alguna; sin embargo, de haberse pagado con posterioridad al plazo en mención, será gasto deducible para la determinación de la renta neta de fuente extranjera de la empresa domiciliada en el país.

Por otra parte, la LIR prohibe explícitamente la compensación de pérdidas de fuente extranjera obtenidas por las sucursales o establecimientos permanentes de empresas domiciliadas en el Perú con sus ingresos por rentas de fuente peruana, el artículo $51^{\circ}$ de la LIR señala que: “... En ningún caso se computará la pérdida neta total de fuente extranjera, la que no es compensable a fin de determinar el impuesto". Con ello, se desincentiva a las empresas peruanas a invertir en el exterior porque las eventuales pérdidas que pudieran tener en el extranjero no podrían compensarse con sus rentas de fuente peruana. 
Las normas tributarias no deberían intervenir en las decisiones de las compañías respecto a sus inversiones, ya sea en su país de origen o en un país extranjero. Las legislaciones que regulan el impuesto a la renta, deberían respetar el Principio de Neutralidad en la Exportación de Capitales.

\section{b) Subsidiaria:}

Una subsidiaria (también denominada como filial) se define como una entidad controlada por otra (conocida como matriz) que posee una personería jurídica propia, lo que determina que sea una sociedad distinta de la matriz, a pesar de que esta tenga una participación dominante en la primera.

Las subsidiarias, que son entidades con vida propia e independiente y que no tienen ningún tipo de vinculación corporativa con la sociedad que la maneja o la controla, no determinan hoy en día créditos indirectos a la empresa controlante

Las rentas que obtenga la subsidiaria van a tributar en el Perú cuando se perciban, por ejemplo, cuando una empresa peruana constituye una subsidiaria en Panamá (quien tiene personería jurídica distinta de la principal), la cual obtiene rentas de fuente extranjera en EEUU, éstas no tributarán Impuesto a la Renta en Perú, sino que recién ello se producirá cuando la subsidiaria en mención decida distribuir dividendos a su matriz peruana. Excepto cuando aplica el régimen de transparencia fiscal internacional que pretende combatir este diferimiento de rentas, en cuyo caso no hay que esperar a que el dividendo sea distribuido efectivamente a Perú.

A fin de verificar si es aplicable el régimen de transparencia fiscal internacional, se debe verificar el cumplimiento de los requisitos regulados en el capítulo XIV de la LIR. Los cuales son:

A. Calificar como Entidad controlada no domiciliada (ECND), debiendo cumplir con las siguientes condiciones:

1. Personería distinta de la de sus socios, asociados, participacionistas o, en general, de las personas que la integran (incluye funds, trust, partnerships, etc.).

2. Estar constituidas o establecida en un país o territorio de baja o nula imposición; o, en el cual las rentas pasivas no se graven; o, se graven con un impuesto igual o inferior al 75\% del Impuesto a la Renta que correspondería a dichas rentas en el Perú. 
3. Propiedad de contribuyentes domiciliados en el país; cuando tiene participación, directa o indirecta, en más del cincuenta por ciento $(50 \%)$ del capital o en los resultados de dicha entidad, o de los derechos de voto en ésta.

B. Las rentas obtenidas por las ECND deben tratarse de rentas pasivas. El artículo 114 de la LIR establece una lista taxativa de aquellos conceptos que califican como rentas pasivas. Si los ingresos que califican como rentas pasivas son iguales o mayores al ochenta por ciento (80\%) del total de los ingresos de la ECND, el total de los ingresos de ésta serán considerados como rentas pasivas.

C. Deben ser rentas pasivas atribuibles (art. 115 de la LIR), es decir, que generen la obligación de pagar el impuesto en el Perú.

No se consideran rentas pasivas atribuibles: (i) las rentas pasivas de la ECND originadas en rentas de fuente peruana, (ii) las que ya hayan sido gravadas con un impuesto a la renta cuya tasa "efectiva" es mayor al 75\% del IR, y (iii) las obtenidas por una ECND cuando el total de su renta neta pasiva es menor a 5 UIT o cuando sus rentas pasivas sean menores o iguales al $20 \%$ de los ingresos totales de la ECND.

El artículo 116 de la LIR reconoce un crédito indirecto partiendo de la premisa que por la transparencia fiscal se desconoce la personalidad jurídica de la sociedad constituida en el extranjero.

La Administración Tributaria reconoce la aplicación del crédito indirecto "de primer grado" en materia de convenios, es decir pueden reconocer como crédito el impuesto a la renta de primera categoría pagado en Chile por las sociedades residentes que distribuyen dividendos a favor de residentes en el Perú, al respecto en el Informe $\mathrm{N}^{\circ}$ 0169-2015-SUNAT (2015) afirma:

"En el caso de una empresa residente en el Perú, accionista principal de una sociedad residente en Chile, la cual es una holding que tiene acciones en otra empresa residente en Chile que realiza actividad operativa, el Impuesto de Primera Categoría pagado en Chile por esta última empresa no puede ser utilizado por la empresa residente en el Perú como crédito en este país".

\subsubsection{El crédito tributario indirecto en los CDI suscritos por el Perú}

Actualmente, el Perú tiene convenios para evitar la doble imposición con los países de Chile, Canadá, Brasil, México, Corea del Sur, Suiza, Portugal y con la República de Corea, así como los países de la Comunidad Andina (Bolivia, Colombia y Ecuador). 
En el caso de estos últimos países, por medio de la Decisión 578 de la Comunidad Andina se aprobó un Régimen (multilateral) para evitar la Doble Tributación y Prevenir la Evasión Fiscal, en su artículo 3 establece que:

"Independientemente de la nacionalidad o domicilio de las personas, las rentas de cualquier naturaleza que éstas obtuvieren, sólo serán gravables en el País Miembro en el que tales rentas tengan su fuente productora, salvo los casos de excepción previstos en esta Decisión. Por tanto, los demás Países Miembros que, de conformidad con su legislación interna, se atribuyan potestad de gravar las referidas rentas, deberán considerarlas como exoneradas, para los efectos de la correspondiente determinación del impuesto a la renta o sobre el patrimonio".

Flores Benavides (2014) afirma:

Como puede verse, entre los países de la Comunidad Andina se ha previsto el método de exención como forma de aliviar la doble imposición. El convenio señala que las rentas que obtengan las personas solo pueden gravarse en el país de la fuente, debiendo cualquier otro país que se atribuya potestad tributaria considerar dichas rentas (las de la misma persona) como exoneradas. En otras palabras, la Decisión 578 regula únicamente situaciones de doble imposición jurídica, no existiendo ninguna otra cláusula referida a la doble imposición económica ni al método del crédito.

Por consiguiente, en ausencia del mecanismo tanto en la ley peruana como en la Decisión 578, las inversiones peruanas en Bolivia, Colombia y Ecuador no darán derecho a aplicar un crédito tributario indirecto.

Por el contrario, en los demás CDI vigentes de los que el Perú forma parte se ha optado por el método del crédito directo como forma de eliminar la doble imposición jurídica; siendo que, cuando se trata de dividendos recibidos por sociedades peruanas de empresas residentes en el otro Estado (doble imposición económica), en todos los casos puede tomarse también un crédito indirecto.

Así, por ejemplo, el artículo 4 del Protocolo del CDI Perú - Chile señala en relación al artículo 23 del convenio ("eliminación de la doble imposición") que, "en el caso de una distribución de dividendos efectuada por una sociedad residente de Chile a un residente de Perú, el crédito en el Perú comprenderá el Impuesto de Primera Categoría [i.e. el impuesto corporativo] pagado por la sociedad en Chile sobre la renta con respecto a la cual se efectúa la distribución de dividendos. Para la aplicación del crédito, el Impuesto de Primera Categoría será considerado después que se haya utilizado la parte del Impuesto Adicional pagado o retenido al accionista". Fluye del texto glosado que, al 
recibir dividendos de una empresa chilena, los residentes peruanos tienen derecho a aplicar un crédito directo e indirecto contra el IR local que grave esos dividendos. (Resaltamos que el artículo 23 de este CDI cuida de precisar que el crédito considerado no podrá exceder, en ningún caso, la parte del IR peruano atribuible a la renta que puede someterse a imposición en Chile). El artículo establece algunas pautas adicionales para la aplicación del crédito indirecto en Perú (por ejemplo, tomar como base imponible la renta considerada antes de los impuestos chilenos, es decir, efectuar un gross- up).

Del mismo modo, el numeral 2 del artículo 23 del CDI Perú - Canadá establece que, en el caso del Perú, la doble imposición se evitará mediante el crédito directo, siempre que el mismo no exceda del impuesto que se pagaría en Perú por las mismas rentas. Añade la cláusula que, "cuando una sociedad que es residente de Canadá pague un dividendo a una persona que es residente de Perú y que la misma controle directa o indirectamente al menos el 10 por ciento del poder de voto en la sociedad, el crédito deberá tomar en cuenta el impuesto pagado en Canadá por la sociedad respecto a las utilidades sobre las cuales tal dividendo es pagado, pero sólo hasta el límite en el que el impuesto peruano exceda el monto del crédito determinado sin considerar este subpárrafo".

Por tanto, las inversiones peruanas en Canadá también gozan de un crédito tanto directo como indirecto cuando se efectúan repartos de dividendos hacia el país (debiendo en este último caso realizarse el gross- up correspondiente). Como es usual, el crédito tiene como límite el monto del impuesto peruano que grave las rentas provenientes de Canadá.

Los cinco CDI restantes (Brasil, México, Corea del Sur, Suiza y Portugal) contienen cláusulas virtualmente idénticas. En todos los casos se contempla expresamente el crédito indirecto, que puede aplicarse hasta el tope del IR peruano sobre las rentas recibidas de los otros Estados. En otras palabras, a excepción de la Decisión 578, en todos los CDI vigentes suscritos por el Perú se permite expresamente aplicar un crédito indirecto a fin de atenuar la doble imposición económica generada por la distribución de utilidades extranjeras hacia inversionistas peruanos.

La única diferencia en estos convenios estaría en el CDI con Chile: éste no exige de modo expreso un porcentaje mínimo de tenencia accionaria para tener derecho al crédito indirecto, mientras que en los otros seis el accionista peruano debe controlar directa o indirectamente, al menos el 10 por ciento del poder de voto en la sociedad extranjera.

No obstante, lo anterior, en la práctica las cláusulas de los CDI sobre crédito indirecto parecen "letra muerta". Es infrecuente ver empresas que, en sus declaraciones anuales de impuestos, incluyan y deduzcan estos créditos. De hecho, no existe regulación, 
procedimiento ni directriz alguna en la ley peruana sobre cómo aplicarlos. (págs. 467468)

\subsubsection{La necesidad de contar con normas internas para poder aplicar el crédito indirecto previsto en los Convenios Internacionales.}

Existe una relación entre los Convenios de Doble Imposición y la legislación interna de los países que lo suscriben, que no resulta ser un simple acuerdo de distribución de potestades tributarias que garanticen la eliminación de la doble imposición, sino que también son mecanismos a través de los cuales se integran los sistemas impositivos de cada País Contratante; en ellos, sus ordenamientos jurídicos tributarios han incorporado cláusulas de carácter material y procedimental que integran la regulación interna de cada Estado firmante sobre la materia en específico.

Es por ello que la doctrina internacional está de acuerdo en que los CDI tienen una fuerte relación con los ordenamientos jurídicos internos de los países que lo suscriben, más que cualquier otro tipo de tratado internacional ya sea de tipo político o económico. En un Convenio se deben respetar los acuerdos plasmados sin vulnerar el derecho de cada Estado de gravar las rentas que le correspondan.

Somos de la opinión que uno de los principales objetivos y, por qué no decirlo, retos del operador del derecho tributario internacional, es el de armonizar las leyes internas con los CDI. Por lo que consideramos que la emisión de normas internas en los tratados es recomendable, mas no necesario. Su emisión puede ayudar para una mejor aplicación del Convenio suscrito, la ausencia de las mismas no significaría la pérdida de un beneficio pactado en un acuerdo internacional, ya que se rigen por cláusulas expresas.

En lo que respecta a la aplicación del crédito indirecto, muchos autores nacionales tienen la opinión de que la ausencia de normas internas que lo regulen dificultaría su aplicación práctica, porque los Convenios Internacionales que tiene suscrito el Perú lo regulan de manera genérica al señalar que se puede tomar el crédito indirecto. Sin embargo, no hacen mayor precisión al pago o a la acreditación del mismo, lo cual nos deja frente a un vacío normativo.

Esto nos pone frente a la problemática materia de nuestra investigación, tenemos Convenios de Doble Imposición vigentes suscritos con distintos países que permiten la 
aplicación del crédito indirecto, sin embargo, en nuestra legislación interna hay un vacío absoluto sobre la regulación del mismo.

Al respecto, el artículo 55 de nuestra Constitución señala que los tratados que celebra el Estado y que están en vigencia forman parte del derecho nacional. Con ello, se alude también a que los convenios internacionales no serían la excepción a la regla, por lo que las disposiciones tributarias contenidas en estos se integran en su totalidad a nuestro ordenamiento jurídico.

En adición a lo ya expuesto, podemos alegar que si el legislador peruano hubiese querido condicionar la aplicación del crédito indirecto a alguna disposición normativa interna, lo hubiese señalado expresamente en cada CDI; esto no es así, por lo que a manera de conclusión, decimos que desde que el mecanismo del crédito indirecto está contenido en los CDI vigentes suscritos por el Estado Peruano, independientemente de que no hayan normas internas que lo limiten, su uso por los contribuyentes es aceptado obligatoriamente.

Además, el solo hecho que el Estado haya decidido no reglamentar la aplicación del crédito indirecto no podría ser una justificación para impedir su utilización, pues ello desvirtuaría la finalidad misma del convenio y podría dar lugar a situaciones de grave arbitrariedad e indefensión.

Se debe reiterar que somos de la idea que, la emisión de normas internas sobre la aplicación del crédito indirecto, si bien no es indispensable, resultaría muy útil para aclarar las dudas que aún existen sobre este mecanismo que sirve para evitar la doble imposición económica internacional.

\subsection{Régimen de transparencia fiscal internacional (RFTI) y la aplicación del crédito} indirecto

El Régimen de Transparencia Fiscal Internacional (RFTI) como lo señala la Ley del Impuesto a la Renta en su artículo $111^{\circ}$, es aplicable a los contribuyentes domiciliados en el país que conduzcan sus inversiones en el extranjero a través de entidades controladas no domiciliadas (ECND), respecto de las rentas pasivas que éstas generen u obtengan (dividendos, intereses, entre otros). 
El objetivo de este régimen es eliminar la posibilidad de que se difiera el reconocimiento de ingresos provenientes de rentas pasivas y el consecuente pago del IR por parte del contribuyente domiciliado (controlador de las inversiones).

Es así que, mediante las reglas de transparencia fiscal se gravará en cabeza de los sujetos domiciliados, las rentas pasivas que obtengan sus entidades ubicadas en paraísos o territorios de baja tributación, lo que se logra imputando como propias las rentas de las mismas.

Para que este régimen se aplique en el Perú, tienen que concurrir las siguientes condiciones que de manera concreta cita la revista América Economía (2013):

a. Existencia de un contribuyente domiciliado en el Perú, obligado a tributar también por sus rentas de fuente extranjera.

b. Control del contribuyente domiciliado en el Perú sobre una entidad establecida en un paraíso fiscal o territorio de baja o nula imposición.

Según el artículo $112^{\circ}$ de la LIR se entiende que una entidad no domiciliada es controlada cuando su propietario es un contribuyente domiciliado en el Perú, lo que se determina al cierre de cada ejercicio.

La calidad de propietario a la que se refiere dicho artículo, le será atribuida al contribuyente domiciliado, cuando este por sí solo, o junto con sus partes vinculadas, tenga una participación directa o indirecta, en más de $50 \%$ del capital, resultados o derechos de voto de la entidad no domiciliada.

Se entiende que las rentas pasivas sobre las cuales se aplica el régimen de transparencia fiscal, de acuerdo a lo señalado en el artículo $114^{\circ}$ de la LIR, son los dividendos, alquileres, regalías, ganancias de capital e intereses. Y que también, calificarán como rentas pasivas, aquellas obtenidas por la entidad controlada cuando realice operaciones con partes vinculadas que sean domiciliadas en el país, siempre y cuando sean deducibles como gasto en el Perú, y además califiquen como renta de fuente extranjera o que calificando como renta de fuente peruana les sea de aplicación una tasa menor al $30 \%$.

Con estos límites aplicables de acuerdo a ley, se busca que las entidades controladas no sean usadas como medios para erosionar la base imponible del impuesto a la renta peruano. 
Figura 2.2

Régimen de Transparencia Fiscal.

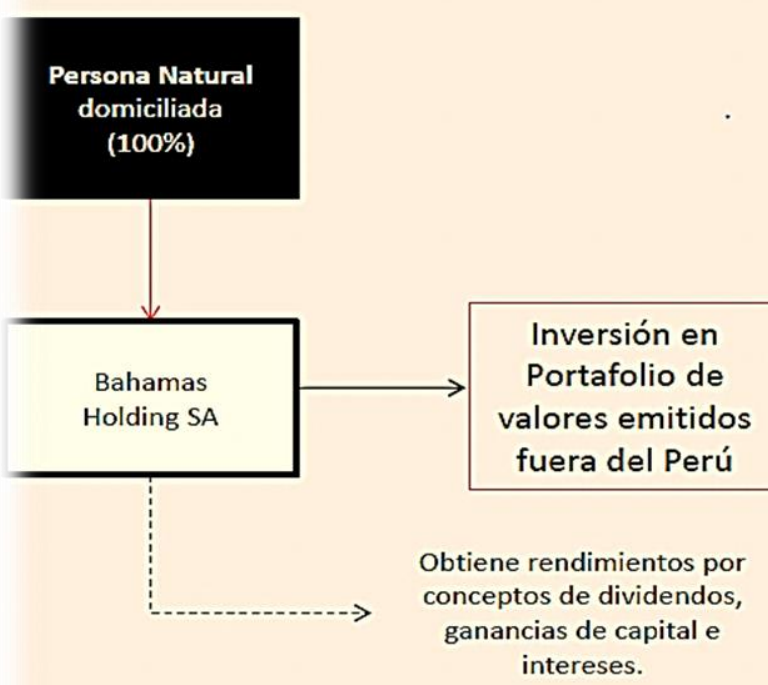

Antes de la entrada en vigencia del Régimen de Transparencia Fiscal Internacional (01.01.2013) los rendimientos obtenidos no estaban gravados en el Perú, sino hasta que sean distribuidas efectivamente por Bahamas SA como dividendos a la PN domiciliada.

Fuente: www.pcw.com - Régimen de Transparencia Fiscal Internacional. Exposición: Arturo Tuesta (2013).

\subsubsection{Crédito por impuesto pagado en el exterior}

El impuesto pagado en el exterior por la entidad controlada no domiciliada con respecto a las rentas netas pasivas que se atribuyan a un contribuyente domiciliado es deducible como crédito.

El uso de este crédito presenta las siguientes limitaciones:

i. El importe que resulte de aplicar la tasa media del contribuyente a las rentas obtenidas en el extranjero.

ii. El importe que no se utilice en el ejercicio gravable, no podrá compensarse en otros ejercicios ni dará derecho a devolución alguna.

Para determinar el crédito, se debe tener en cuenta lo dispuesto en el artículo $64^{\circ}-\mathrm{C}$ del Reglamento de la Ley del Impuesto a la Renta y su remisión al artículo $58^{\circ}$ de la citada norma, cuando señalan que:

- El impuesto es el efectivamente pagado en el exterior por la entidad controlada no domiciliada respecto de las rentas pasivas atribuibles a los contribuyentes 
domiciliados, sea que ese impuesto haya sido pagado en el país en el que está constituido, establecido o en el que sea residente, domiciliada, y/o en otro país.

- Si la entidad controlada no domiciliada paga un impuesto en el exterior que grava las rentas netas pasivas atribuibles y otras rentas netas, el importe del crédito por impuesto pagado en el exterior será el correspondiente a la parte que gravó las rentas pasivas, lo que se determinará aplicando al referido impuesto el coeficiente que resulte de dividir las rentas netas pasivas atribuibles entre el total de las rentas netas de la entidad controlada no domiciliada gravadas en el exterior.

Además, la misma norma reglamentaria nos señala que no será deducible del impuesto en el país que grava las rentas pasivas atribuidas, el impuesto pagado en el exterior, si dichas rentas son de fuente peruana.

No se podrá deducir, tampoco, el impuesto que grave los dividendos y cualquier otra forma de distribución de utilidades, que hayan sido distribuidos al contribuyente domiciliado en el país, sin perjuicio de las deducciones que señala la LIR en el inciso e) del artículo $88^{\circ}$.

\subsection{Legislación comparada}

\subsubsection{Tratamiento del crédito indirecto en Colombia}

A partir del 2017, el legislador decidió unificar los impuestos de renta y CREE en un solo impuesto. Durante el 2017, la tarifa del impuesto a la renta será del 34\% más 6\% de sobretasa, y para el 2018 del 33\% más 4\% de sobretasa. La sobretasa solo aplica a las empresas que tengan utilidades mayores a $\$ 800$ millones de pesos.

Anteriormente, las personas jurídicas domiciliadas en Colombia estaban sujetas a los siguientes impuestos: el impuesto básico de renta y el impuesto sobre la renta para la equidad-CREE- junto con su sobretasa.

A fin de determinar el importe máximo del descuento permitido se debe verificar la fórmula establecida en el artículo 254 del Estatuto Tributario, pero previamente se mencionará las modificaciones más relevantes realizadas a este artículo.

\subsubsection{Ley 1430 del 2010}


Modificó el artículo 254 del estatuto tributario para reconocer que no solo los contribuyentes nacionales, sino también los extranjeros personas naturales con cinco años o más de residencia continua o discontinua en el país, tienen derecho al descuento o crédito tributario por impuestos pagados en el exterior sobre sus rentas de fuente extranjera; así como el descuento o crédito tributario no solo para sus filiales, sino también en relación con las subsidiarias del exterior. Sin embargo; no se definió si el alcance del descuento o crédito tributario indirecto está o no limitado a un segundo nivel de inversión.

Cabe señalar que si bien La Ley 1430 del 2010 modifico el artículo 254 del Estatuto Tributario estableciendo el requisito del 15\% de participación accionaria directa o indirecta en el capital de la empresa de la que se recibe dividendos o de la subsidiaria indirecta para la procedencia del beneficio, este requisito fue declarado inconstitucional por la Corte Constitucional de Colombia por medio de la Sentencia C-913/11 del 6 de diciembre de 2011, según lo señalado en el Comunicado $N^{\circ} 48$ de diciembre 6 y 7 de 2011 emitido por dicho Tribunal.

\subsubsection{Ley 1607 de 2012}

Introdujo algunos cambios en el impuesto a la renta, para Pino Castillo (2013) las medidas mas resaltantes son:

\footnotetext{
“(...) la tarifa general del impuesto de renta para personas jurídicas nacionales, del 33\% la bajó al 25\%. Para las personas jurídicas extranjeras y naturales extranjeras sin residencia la dejó en el 33\%(...) Creó el impuesto sobre la renta para la equidad-CREE fijando como sujeto pasivo a las personas jurídicas, nacionales y extranjeras contribuyentes declarantes del impuesto a la renta, sin incluir las personas jurídicas sin ánimo de lucro y tampoco las Zonas Francas declaradas al 31 de diciembre de 2012 o con solicitud en trámite y sus usuarios presentes y futuros".
}

\subsubsection{Ley 1739 de 2014}

Con el artículo 16 de la Ley 1739 del 2014 se adicionó el artículo 22-5 a la Ley 1607 del 2012, con el cual quedó establecido que en las declaraciones del impuesto sobre la renta para la equidad -CREE- de los años gravables 2015 y siguientes, al impuesto del CREE inicialmente obtenido sobre la base gravable final, aumentado con la nueva sobretasa del 
CREE (establecida en los artículos 21 a 24 de la Ley 1739 del 2014), se le podrá restar a manera de descuento el valor de los impuestos pagados en el exterior; es decir, quedó permitido que en la declaración del CREE se podrá restar el impuesto de renta o su similar que se haya pagado en otros países sobre rentas obtenidas en los mismos, pero que son rentas que al traerlas al formulario del CREE vuelven a producir impuesto CREE ante el Gobierno colombiano.

\subsubsection{Ley 1819 de 2016}

Los cambios introducidos por la Ley 1819 empezaron a regir a partir del 01 de enero de 2017, siendo derogadas las leyes 1607 de 2012 y 1739 de 2014, que regulaban el impuesto sobre la Renta para la equidad CREE.

Se propone una disminución de la tarifa del impuesto sobre la renta de personas jurídicas a partir del año 2017, que disminuirá en tres puntos porcentuales para el 2018(sumando la correspondiente a renta y sobretasa), siendo el esquema tributario el siguiente:

Tabla 2.2

Esquema tributario de Colombia.

\begin{tabular}{lccc}
\hline Concepto & $\mathbf{2 0 1 7}$ & $\mathbf{2 0 1 8}$ & $\mathbf{2 0 1 9}$ y s.s. \\
\hline Tarifa general & $34 \%$ & $33 \%$ & $33 \%$ \\
Sobretasa & $6 \%$ & $4 \%$ & N/A \\
Total & $40 \%$ & $-37 \%$ & $33 \%$ \\
\hline
\end{tabular}

La nueva sobretasa para el impuesto a la renta, aplicara a partir de una base gravable igual o superior a ochocientos millones de pesos.

\subsubsection{Crédito tributario indirecto en Colombia}


Con la normativa actual, los contribuyentes del impuesto sobre la renta pueden tomar un crédito tributario indirecto sobre los dividendos que perciban de sociedades del exterior, conforme al artículo 254 del Estatuto Tributario "Cuando se trate de dividendos o participaciones provenientes de sociedades domiciliadas en el exterior, habrá lugar a un descuento tributario en el impuesto sobre la renta y complementarios por los impuestos sobre la renta pagados en el exterior".

El crédito tributario indirecto de primer nivel, permite al contribuyente colombiano acreditar el impuesto pagado en el exterior por las utilidades que se reparte como dividendo de la siguiente manera según el literal a) del artículo 254 del Estatuto Tributario)."El valor del descuento equivale al resultado de multiplicar el monto de los dividendos o participaciones por la tarifa del impuesto sobre la renta a la que hayan estado sometidas las utilidades que los generaron multiplicado por la proporción de que trata el literal h) de este inciso".

Por el año 2016, para el caso de las personas jurídicas, el valor del impuesto que se puede tomar como descuento en el impuesto de renta será el equivalente a multiplicar la tarifa del impuesto de renta del exterior, por el valor de los dividendos y multiplicarlo por el $62.5 \%$, que corresponde a la proporción del impuesto básico de renta sobre el total de la carga tributaria.

El siguiente ejemplo mencionado por José Andrés Romero Tarazona en la relatoría del 8vo. Encuentro Regional Latinoamericano del IFA (Romero, 2016), nos es útil para entender el valor máximo que se puede tomar como descuento tributario indirecto en el caso de una sociedad, para lo cual asumimos que el valor del impuesto en el país de la fuente es del $20 \%$ y que los dividendos percibidos ascienden a 1000 .

Figura 2.3

Esquema tributario de Colombia.

$$
\text { Descuento }=\frac{\text { TRyC } *(\text { TarifaExt } * \text { Dividendo })}{\text { TRyC }+ \text { TCREE }+ \text { STCREE }} \|
$$


Donde:

- TRyC es la tarifa del impuesto sobre la renta y complementarios aplicable al contribuyente por la renta de fuente extranjera.

- TCREE es la tarifa del Impuesto sobre la Renta para la Equidad CREE aplicable al contribuyente por la renta de fuente extranjera.

- STCREE es la tarifa de la sobretasa al impuesto sobre la renta para la Equidad CREE aplicable al contribuyente por la renta de fuente extranjera.

- Tarifa Ext es la tarifa del impuesto sobre la renta en el exterior.

- Dividendo es el monto de los dividendos percibidos.

Resultando:

Descuento $=$

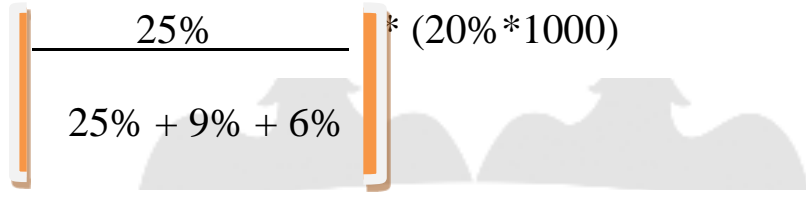

Descuento $=62.5 \% * 200$

En este caso el valor del crédito tributario que la compañía puede tomar seria de 125.

Cabe mencionar que, para tener derecho al descuento mencionado según el literal c) del artículo 254 del Estatuto Tributario "el contribuyente nacional debe poseer una participación directa en el capital de la sociedad de la cual recibe los dividendos o participaciones (excluyendo las acciones o participaciones sin derecho a voto)".

Asimismo, se permite el crédito tributario indirecto de segundo nivel al señalar el literal c) del artículo 254 del Estatuto Tributario:

“(...) el contribuyente nacional deberá poseer indirectamente una participación en el capital de la subsidiaria o subsidiarias (excluyendo las acciones o participaciones sin derecho a voto). Las participaciones directas e indirectas señaladas en el presente literal deben corresponder a inversiones que constituyan activos fijos para el contribuyente en Colombia, en todo caso haber sido poseídas por un periodo no inferior a dos años.

PARÁGRAFO. El impuesto sobre la renta pagado en el exterior, podrá ser tratado como descuento en el año gravable en el cual se haya realizado el pago o en cualquiera de los 
cuatro (4) periodos gravables siguientes sin perjuicio de lo previsto en el artículo 259 del Estatuto Tributario".

\subsubsection{Tratamiento del crédito indirecto en Chile}

Los impuestos en Chile cambiaron a partir del 01 de enero de 2017. Los contribuyentes que deban declarar sus rentas efectivas determinadas sobre la base de un balance general según contabilidad completa, deberán sujetarse a uno de los siguientes regímenes:

1. Régimen de renta efectiva según contabilidad completa, con imputación total del crédito por Impuesto de Primera Categoría (en adelante IDPC) en los impuestos finales, denominado también alternativamente como "régimen de renta atribuida" o "régimen de la letra A), del artículo 14 de la Ley sobre Impuesto a la Renta". El IDPC será de $25 \%$ y las rentas deben ser declaradas por sus dueños en el mismo año en que se devenguen, en relación a su participación, con imputación total del IDPC como crédito.

2. Régimen de renta efectiva según contabilidad completa, con imputación parcial del crédito por IDPC en los impuestos finales, denominada también como "régimen de imputación parcial de crédito", "sistema semi integrado" o "régimen de la letra B), del artículo 14 de la Ley sobre Impuesto a la Renta”. El IDPC será de $27 \%$ y los dueños pagaran los impuestos finales cuando realicen retiros o perciban dividendos, pero tendrán como crédito el $65 \%$ del IDPC $(17.55 \%)^{3}$.

\subsubsection{Crédito por impuestos soportados en el extranjero}

La Ley $\mathrm{N}^{\circ} 19.247$, publicada en el Diario Oficial de 15 de septiembre de 1993, mediante su artículo $1^{\circ}$, letra f), incorporó a la Ley sobre Impuesto a la Renta (en adelante LIR), en su título II, el párrafo 6, denominado "De las normas relativas a la doble tributación internacional", que introdujo el artículo 41 A de la LIR.

El sistema establecido por la LIR para determinar los créditos por impuestos soportados en el extranjero que podrán ser deducidos de los impuestos a la renta en Chile,

\footnotetext{
${ }^{3}$ Las instrucciones relacionadas con los nuevos regímenes de tributación sobre renta efectiva en base a contabilidad completa fueron impartidas por el Servicio de Impuestos Internos de Chile en la Circular `49 del 2016 (Información que figura en su página web: http://www.sii.cl/documentos/circulares/2016/circu49.pdf.
} 
distingue aquellos casos en que resulte aplicable un Convenio para evitar la Doble Tributación Internacional (en adelante CDTI) que se encuentre vigente, y en el que se haya acordado conceder créditos para disminuir o eliminar la doble tributación internacional, lo que se encuentra regulado en el artículo $41 \mathrm{C}$ de la LIR(conocido como sistema bilateral), y aquellos en que no resulte aplicable dicha clase de convenios, lo que se encuentra regulado en el artículo 41 A de la LIR(conocido como sistema unilateral), relativo a las rentas correspondientes a dividendos y retiros de utilidades; rentas de agencias, establecimientos permanentes y aquellas que resulten de la aplicación del artículo 41 G de la LIR; y rentas por el uso de marcas, patentes, fórmulas, asesorías técnicas y otras prestaciones similares que hayan sido gravadas en el extranjero ${ }^{4}$.

\subsubsection{Crédito Total Disponible (en adelante CDT)}

Consiste en la sumatoria de los distintos créditos por Impuestos Pagados en el Extranjero en adelante IPE) calculados renta por renta, imputables en contra de los impuestos de Primera Categoría (en adelante IDPC), Global Complementario (en adelante IGC), Adicional (en adelante IA) o Único de Segunda Categoría (en adelante IUSC).

El CTD en el sistema unilateral solo tendrá aplicación respecto de las rentas consistentes en dividendos y retiros de utilidades.

Conforme lo establece la letra a), del $N^{\circ} 3$, de la letra A.-, del artículo 41 A de la LIR, en el caso del sistema unilateral de créditos, el CTD, es decir, la suma de todos los créditos por concepto de dividendos o retiros de utilidades, se deberá agregar a la base imponible del IDPC.

\subsubsection{Registro de Inversiones en el Extranjero}

Para que los contribuyentes que hayan efectuado inversiones en el exterior por las cuales obtengan rentas provenientes de dividendos, retiros, agencias o establecimientos permanentes y las rentas pasivas del artículo $41 \mathrm{G}$ de la LIR, establecidas en las letras A.y B.- del artículo 41 A, respectivamente, puedan hacer uso del crédito por IPE, exista o

\footnotetext{
${ }^{4}$ El Servicio de Impuestos Interno instruye sobre las modificaciones efectuadas por la Ley $\mathrm{N}^{\circ} 20.780$ de 2014 y Ley $\mathrm{N}^{\circ} 20.899$ de 2016 a los artículos $41 \mathrm{~A}, 41 \mathrm{~B}$, y $41 \mathrm{C}$, de la LIR, que rigen a contar del $1^{\circ}$ de enero de 2017, en la Circular $N^{\circ} 48$ del 2016 (Información que figura en su página web).
} 
no CDTI con el país de donde provienen dichas rentas, deberán inscribir previamente sus inversiones en el "Registro de Inversiones en el Extranjero" (en adelante RIE).

\subsubsection{Tratamiento del Crédito por IPE respecto de países con los cuales no existe CDTI vigente}

La Ley $\mathrm{N}^{\circ} 20.899$, elimina ciertas limitaciones para hacer uso de los créditos por IPE, puesto que a partir del $1^{\circ}$ de enero de 2017 , se podrá hacer valer como crédito el IPE soportado por las sociedades subsidiarias de la entidad que remesa las utilidades a Chile, aún cuando tales subsidiarias no estén domiciliadas en el mismo país, siempre que Chile tenga vigente un CDTI u otro que permita el intercambio de información para fines tributarios, con el país en que tengan domicilio las mencionadas sociedades subsidiarias. Asimismo, podrá utilizarse el crédito por el IPE soportado por las sociedades subsidiarias en la generación de las utilidades que son percibidas por la sociedad extranjera y que luego son remesadas a Chile, ya sea que exista o no, impuesto de retención sobre la distribución de utilidades y cualquiera sea su tasa, observando en todos los casos lo límites legales establecidos.

Es decir, a partir del $1^{\circ}$ de enero de 2017 , se puede hacer valer como crédito a que se refieren los artículos 41 A y $41 \mathrm{C}$, los impuestos pagados por subsidiarias de la empresa que remesa las utilidades a Chile, siempre que las subsidiarias se encuentren domiciliadas en un país con el que se encuentre vigente un CDTI u otro que permita el intercambio de información para fines tributarios, en el cual se hayan aplicado los impuestos acreditables en Chile

\subsubsection{Determinación del CTD por dividendos o retiros de utilidades}

En estos casos, el CTD, que deberá ser utilizado en la determinación del crédito por IPE, corresponderá a la cantidad menor entre:

- Primer límite: La suma de los impuestos pagados o retenidos por el Estado extranjero sobre estas rentas, calculado de manera separada por cada una de ellas.

- Segundo límite: El 32\% de una cantidad tal que, al restarle el mismo porcentaje aplicado, el resultado sea el monto neto del dividendo y/o retiro percibido, respecto del cual se calcula el crédito por IPE. Esta suma se obtiene luego de 
multiplicar el monto percibido, debidamente convertido a moneda nacional a la fecha de percepción y reajustado al término del ejercicio, en los casos que resulte procedente, por el factor 0,470588, el que resulta de dividir 32 por 68 .

Los IPE que deben considerarse en el cálculo del CTD son aquellos que gravaron de forma directa el dividendo o retiro percibido; esto es, aquellos que hayan debido pagar o que les hayan retenido en el extranjero por las referidas rentas. La norma permite considerar en el cálculo del CTD los siguientes impuestos:

i. El impuesto pagado por la sociedad extranjera respecto de sus propias rentas, que deberá ser calculado proporcionalmente; para ello, la LIR ordena reconstituir la base bruta de la renta que corresponda a los dividendos o retiros de utilidades a nivel de la empresa desde la que se pagan, agregando primero el impuesto de retención y adicionado este, el impuesto a la renta de la respectiva empresa.

Lo anterior, se puede ejemplificar de la siguiente manera:

Figura 2.4

Determinación del crédito por dividendos

\begin{tabular}{|c|c|c|}
\hline $\begin{array}{l}\text { Dividendo liquido percibido } \\
\text { del exterior }\end{array}$ & $\$ 250.000$ & Impuesto \\
\hline $\begin{array}{l}\text { Impuesto retenido (tasa } \\
10 \% \text { ) }\end{array}$ & $\frac{250.000 \times 10 \%}{0,90}=\$ 27.778$ & $\begin{array}{l}\text { a la renta } \\
\text { de la }\end{array}$ \\
\hline $\begin{array}{lr}\text { Impuesto } & \text { corporativo } \\
\text { pagado por sociedad } \\
\text { extranjera sobre la parte } \\
\text { correspondiente } & \text { al } \\
\text { dividendo (tasa 25\%) } & \\
\end{array}$ & $250.000+27.778=\frac{\$ 277.778 \times 25 \%}{0,75}=\$ 92.593$ & $\begin{array}{l}\text { empresa } \\
\$ 92.593\end{array}$ \\
\hline
\end{tabular}

ii. El impuesto a la renta pagado por una o más sociedades en la parte de las utilidades que repartan a la empresa que remesa dichas utilidades a Chile, siempre que esta última posea directa o indirectamente el $10 \%$ o más del capital de las sociedades subsidiarias y se verifique alguna de las siguientes condiciones: 
- Que las sociedades subsidiarias estén domiciliadas en el mismo país de la entidad que remesa las utilidades a Chile.

- Que las sociedades subsidiarias estén domiciliadas en un país con el cual Chile tenga vigente un CDTI.

- Que las sociedades subsidiarias estén domiciliadas en un país con el cual Chile tenga vigente un acuerdo que permita el intercambio de información para fines tributarios.

En la Dirección Nacional de Chile se recibió una consulta sobre la actual ley del impuesto a la renta, específicamente sobre la aplicación del artículo 41-C, respecto a la situación de una empresa chilena que posee inversiones en el exterior (2017):

\section{ANTECEDENTE.}

Se consulta por la situación de una empresa chilena que posee inversiones en una sociedad holding en Australia, la cual a su vez participa en sociedades subsidiarias domiciliadas en Canadá, Brasil, Reino Unido, Estados Unidos y Bélgica que le distribuyen utilidades a la sociedad holding en Australia que luego esta remesa a Chile.

\section{$(\ldots)$ \\ II. ANALISIS}

(...) Ahora bien, la Ley $\mathrm{N}^{\circ} 20.899$ publicada el 8 de febrero de 2016, incorporó un párrafo final al inciso $2^{\circ}$, del $\mathrm{N}^{\circ} 2$, del artículo $41 \mathrm{C}$ de la LIR, vigente a contar del $1^{\circ}$ de enero de 2017, que aplica a las rentas gravadas en el extranjero que se perciban o devenguen, según corresponda, a partir de esta fecha. Dicho precepto legal indica lo siguiente: "También se aplicará dicho crédito, cuando las sociedades subsidiarias referidas estén domiciliadas en un tercer país con el cual se encuentre vigente un convenio para evitar la doble tributación internacional $\mathrm{u}$ otro que permita el intercambio de información para fines tributarios, en el cual se hayan aplicado los impuestos acreditables en Chile". En consecuencia, si las sociedades domiciliadas en Canadá, Brasil, Reino Unido, Estados Unidos y Bélgica reparten utilidades a la sociedad holding en Australia, que hayan sido gravadas con impuestos a la renta definitivos y acreditables en Chile, podrán utilizarse de crédito en nuestro país, siempre que dichas utilidades sean remesadas a Chile por la sociedad holding en Australia y siempre que Chile tenga vigente un convenio para evitar la doble tributación u otro que permita el intercambio de información para fines tributarios con los países de Canadá, Brasil, Reino Unido, Estados Unidos y Bélgica.

$(\ldots)$ 


\section{CONCLUSIÓN}

En conformidad a lo señalado y al tenor de su consulta, en principio podría usar el crédito extranjero por el impuesto que afecta a las rentas distribuidas por la sociedad holding australiana, siempre que cumpla los requisitos señalados y demás establecidos en el respectivo convenio y en el Párrafo $6^{\circ}$, del Título II de la LIR. 


\section{CAPÍTULO III: ASPECTOS A CONSIDERAR EN LA IMPLENTACIÓN DEL MECANISMO DEL CRÉDITO INDIRECTO EN EL PERÚ}

\subsection{Análisis del costo-beneficio de la incorporación del crédito indirecto en el Perú}

Creemos que la utilización del crédito indirecto dotaría a las compañías inversoras peruanas de un régimen moderno que grave de manera razonable sus rentas.

El crecimiento del país sería aún mayor, puesto que el Perú se constituiría en un país que concentre capitales sin someterlo a imposiciones excesivas.

La reinversión en nuestro país de los beneficios obtenidos en el exterior sería posible, además que ello aliviaría el problema de la doble imposición económica internacional.

\subsection{Aplicación del crédito indirecto - Caso Práctico}

Para poder demostrar cómo nos podría beneficiar la incorporación del crédito indirecto en nuestra legislación, nos planteamos el siguiente caso:

Tenemos el caso de la empresa domiciliada Inka S.A.C. que es accionista de la empresa norte americana House Green. Vamos a suponer que la tasa del Impuesto a la Renta (IR) empresarial en Perú es de $30 \%$ y en Estados Unidos será de 25\%, además este último, va a gravar la distribución de dividendos a los accionistas extranjeros con una tasa del 20\%. En el ejercicio fiscal 2016, House Green obtiene rentas por \$120 dólares. Entonces, si aplicamos la tasa empresarial americana de 25\%, la utilidad después de impuestos en ese país será de $\$ 90$ dólares.

Hasta allí no se observa mayor implicancia tributaria, pero qué sucede si la empresa peruana Inka S.A.C. decide repatriar la utilidad vía distribución de dividendos, esto implica que la empresa House Green tendrá que retener un impuesto de $20 \%$ (es decir \$18 dólares) en su país.

Entonces se tendrá que de los $\$ 90$ dólares devengados a favor de la empresa peruana están afectos al IR de 30\%, lo que es equivalente a \$27 dólares. Al final, tenemos 
que el rendimiento neto que obtiene la empresa Inka S.A.C. será de \$45 dólares, lo cual supone una carga tributaria combinada de $62.5 \%$ sobre los $\$ 120$ dólares iniciales que planteamos en el caso práctico en cuestión.

Si observamos el costo tributario final en el caso propuesto, la empresa establecida en Perú (Residencia) tiene que pensarlo dos veces antes de invertir en Estados Unidos (Fuente), cuando menos, si quiere utilizar una filial peruana.

El caso planteado describe las dos formas más conocidas de doble imposición internacional. Cuando un mismo sujeto es sometido a imposición sobre las mismas rentas por dos jurisdicciones distintas, se trata de doble imposición jurídica. En el caso práctico, se observa la utilidad de $\$ 90$ dólares gravada con el impuesto al dividendo americano dando como resultado $\$ 18$ dólares (respecto del cual Inka S.A.C. es contribuyente) y a la vez con el Impuesto a la Renta peruano de \$27 dólares.

Por otro lado, cuando unas mismas rentas son gravadas a la vez por dos jurisdicciones distintas, aunque en manos de sujetos "legalmente" distintos, estamos ante un caso de doble imposición económica. Ello ocurriría con las ganancias de House Green (\$120 dólares), afectas al impuesto empresarial americano (25\%) de \$30 dólares y posteriormente, gravadas en manos de Inka S.A.C. con un tributo de \$27 dólares.

Después de apreciar los efectos nocivos que generan ambas formas de doble imposición al desalentar las inversiones y el flujo de bienes y capitales, estamos de acuerdo con la doctrina nacional e internacional cuando expresan de manera casi unánime que ambas deben ser combatidas. Es aquí donde surge la idea de incorporar el crédito indirecto como uno de los principales métodos utilizados para aliviar o disminuir la doble imposición económica internacional.

\subsection{Propuesta legislativa}

La Ley del Impuesto a la Renta no admite la posibilidad de aplicar el crédito tributario indirecto como medida para evitar la doble imposición económica.

Por ello, la legislación peruana debe incorporar en su artículo $88^{\circ}$ el derecho a descontar del monto del impuesto a la renta el impuesto pagado en el extranjero, este descuento no debe exceder el monto del impuesto que deba pagar el contribuyente en el Perú por esas mismas rentas. 
Pese a que existe una muy buena iniciativa legislativa en trámite para incorporar esta figura, no se le ha dado prioridad; a decir verdad, creemos que es una propuesta legislativa estancada (el estado actual de dicha propuesta según el portal web del Congreso de la República ${ }^{5}$ indica que aún está en "estado de comisión”). Nos referimos al Proyecto de Ley No. 3599/2013-CR, presentado en junio del 2014 ante el Congreso de la República, por el que se plantea incorporar un inciso f) al artículo 88 de la LIR a fin de regular expresamente la figura del crédito tributario indirecto.

En la Exposición de motivos del Proyecto bajo comentario se ha reconocido que la evolución del sistema tributario peruano no se ha dado en concordancia con el crecimiento económico que el Perú ha reflejado en los últimos años. Para ello basta ver nuestra legislación tributaria que en su mayoría ha sido aprobada en un contexto en que el país era un importador de capitales, centrando la atención en la imposición de las rentas generadas en el ámbito local.

Si bien es cierto, hoy en día se están reestructurando las normas tributarias en materia de exportación, otorgando ciertos beneficios, incentivos, entre otras medidas que hagan del Perú un país más atractivo para la inversión a nivel mundial y que tenga una posición más competitiva en la región. No podemos dejar de lado el problema de la doble imposición económica internacional generado por la ausencia del crédito indirecto.

Analizando la legislación comparada, la Exposición de Motivos que es materia de análisis hace hincapié en que otros países como Colombia, Chile, Argentina y Estados Unidos, ya han incorporado variantes de este mecanismo en sus normas interna.

Entonces, después de exponer el escenario al que le hacen frente los créditos por impuestos pagados en el extranjero (se admite el crédito directo, existe un proyecto de ley para incorporar el indirecto), estamos de acuerdo con las características planteadas por el Proyecto de Ley No. 3599/2013-CR que deberían considerarse al incorporar la figura del crédito indirecto en nuestra normativa, con algunas variantes:

- Se debe incluir el impuesto pagado por las empresas en distintos niveles, cuando los dividendos distribuidos al Perú por la afiliada extranjera hayan sido, a su vez, recibidos de otras sub-afiliadas ubicadas en la misma o en otras jurisdicciones.

${ }^{5}$ http://www2.congreso.gob.pe/sicr/tradocestproc/clproley2011.nsf. 
- El contribuyente peruano debe poseer una participación directa o indirecta en el capital de la sociedad extranjera, de la cual recibe los dividendos, no inferior al diez por ciento $(10 \%)$.

- Para que se tenga derecho a la deducción, el impuesto deberá ser efectivamente pagado en cada jurisdicción con la constancia emitida por la autoridad tributaria respectiva o en su defecto, con documento fehaciente.

- El impuesto a la renta pagado en el exterior puede utilizarse como crédito indirecto en el ejercicio fiscal en que haya sido pagado o en cualquiera de los cuatro (4) ejercicios fiscales siguientes.

- El crédito indirecto no impide la aplicación del crédito directo, siempre que, en su conjunto, no excedan del impuesto a la renta peruano aplicable a las respectivas rentas extranjeras.

Antes de concluir con el tema objeto de nuestra tesis, se hizo la investigación correspondiente para obtener mayor información sobre el estado de este Proyecto normativo, el resultado fue poco alentador. Así que, si bien es cierto se debe saludar la iniciativa legislativa, también se debe decir que es un Proyecto que al parecer ha quedado en el olvido del legislador, así que lo que buscamos con el desarrollo del tema es alentar el debate sobre una propuesta que ha nuestro parecer no se le ha dado la importancia que merece. 


\section{CONCLUSIONES}

- La falta de regulación del crédito indirecto en el Perú como mecanismo para evitar la doble imposición económica, conlleva a que nuestras empresas no busquen invertir en el exterior. Es decir, si una empresa peruana decide invertir en otro país, y obtiene rentabilidad, esto le significaría el pago de impuestos por las ganancias obtenidas en el exterior. Además, en caso haya distribución de dividendos la empresa matriz peruana tendría que pagar impuestos en el país por haber percibido renta de fuente extranjero.

- Actualmente, el legislador se ampara argumentando que la situación descrita se evitaría si es que el país donde se generó esa renta tiene celebrado un Convenio para evitar la doble imposición (CDI) con el Perú. Lo cual no es la solución más acertada debido a que el Perú sólo cuenta con este tipo de convenios con siete países (Chile, Canadá, Brasil, México, Portugal, Corea y Suiza) y un Tratado que es el de la Decisión 578 de la Comunidad Andina (integrada por Bolivia, Ecuador, Colombia y Perú).

- Si el propio Estado se ha obligado vía convenios internacionales vigentes a incluir el crédito indirecto como mecanismo para eliminar o mitigar la doble imposición económica, con excepción de la Decisión 578 de la Comunidad Andina, surge la interrogante de porque no incorporarlo de manera permanente con la creación del inciso f) del artículo 88 en la Ley del Impuesto a la Renta, si de lo descrito a lo largo de este trabajo vemos que la ausencia de este mecanismo no contribuye a fomentar las inversiones, caso contrario se daría con su aplicación por el impacto positivo que estamos seguras tendría en el incremento de las inversiones peruanas en el exterior, el crecimiento económico del país, el posicionamiento del Perú como nación que respeta y promueve sus convenios tributarios, así como eventualmente incentivar a determinados contribuyentes como es el caso de las personas naturales a repatriar y declarar los rendimientos de sus inversiones, entre otros beneficios.

- Por otro lado, y a pesar de las posibles dudas que pueden surgir de la aplicación del crédito indirecto, existe pleno derecho a utilizarlo (i) por el principio de aplicación 
directa y prevalencia de los tratados, reconocido a nivel constitucional; (ii) porque en los CDI vigentes no se ha dispuesto ninguna remisión a la ley interna, como sí se ha hecho para otros casos; y (iii) porque la inacción del Estado no puede perjudicar el legítimo derecho que asiste a los contribuyentes de acceder a los beneficios previstos por los CDI.

- A manera de recomendación, vemos que es necesario que en nuestra legislación se aprueben normas de desarrollo sobre el crédito indirecto otorgado vía convenio, cuidando que estas no alteren su finalidad que es la de evitar la doble imposición económica.

- Otro punto muy importante es que debería permitirse arrastrar el crédito directo del impuesto a la renta a los cuatro ejercicios posteriores, para ello se requiere modificar el inciso e) del artículo 88 de la LIR; asimismo, debe señalarse taxativamente que se puede considerar como gasto en caso de que no se arrastre como crédito.

- En caso de no tomarse la medida de incorporar el inciso f) al artículo $88^{\circ}$ de la LIR a fin de solucionar la problemática de la doble imposición económica, es necesario suscribir la mayor cantidad de CDI con los países de los principales destinos de inversión peruana en el exterior.

- Para concluir, somos de la opinión de que la inclusión del crédito indirecto nivelaría la posición entre las empresas que operan en el exterior a través de subsidiarias o filiales, con las que operan simplemente con sucursales extranjeras. 


\section{REFERENCIAS}

América Economía. (20 de septiembre de 2013). Obtenido de https://www.americaeconomia.com/analisis-opinion/peru-la-altura-de-latransparencia-fiscal-internacional

Bassallo Ramos, C. (s.f.). El método de imputación para evitar la doble imposición en el CDI modelo OCDE frente a la Ley del Impuesto a la Renta a propósito de la limitación temporal contenida en la legislación interna. Obtenido de ifaperu: http://www.ifaperu.org/uploads/articles/318_03_bassallo.pdf

Benavides, R. F. (2015). El Crédito Tributario Indirecto en la Legislación Interna y en los Convenios Para Evitar la Doble Imposición Suscritos por el Perú . Derecho \& Sociedad (43), 461-472.

Chiarella Privette, J. (junio de 2010). Inversión Extranjera y Convenios para evitar la Doble Imposición. Cuadernos Tributarios(30).

Cores Ferradas, R. (s.f.). El Crédito por Impuesto a la Renta Pagado en el Extranjero. Obtenido de ifaperu:

http://www.ifaperu.org/uploads/articles/270_04_ct29_rcf.pdf

Flores Benavides, R. (s.f.). El Crédito Tributario Indirecto en la Legislación Interna y en los Convenios Para Evitar la Doble Imposición suscritos por el Perú. Revista Derecho \& Sociedad(43). Obtenido de estudiograu:

http://www.estudiograu.com:8080/web/publicaciones/El_cr\%C3\%A9dito_tribut ario_indirecto_en_la_legislaci\%C3\%B3n_interna_y_en_los_Convenios_Para_E vitar_la_Doble_Imposici\%C3\%B3n_Suscritos_por_el_Per\%C3\%BA.pdf

Liu Arévalo, R., \& Vargas León, L. (2006). El crédito por impuesto a la renta extranjero: comentarios y críticas a la ley peruana. Ius et Veritas(33).

Mariño Barbosa, J. D. (2009). El crédito tributario por impuestos pagados en el exterior. Un análisis desde la perspectiva del derecho comparado de una medida unilateral para evitar la doble tributación. Revista de la Maestría en Derecho Económico(5), 291-343.

Pino Castillo, E. (14 de enero de 2013). consultame.co. Obtenido de https://www.consultame.co/index.php/articulos/aspectos-contables-ytributarios/aspectos-tributarios/procedimiento-tributario/526-resumen-ejecutivode-la-ley-de-reforma-tributaria-ley-1607-de-2012

Plazas Vega, M. (2008). Estudios de derecho internacional tributario. Los convenios de doble imposición. Bogotá, Colombia: Legis Editores.

Rohatgi, R., \& Idrovo, J. M. (2008). Principios Básicos de Tributación Internacional ( $1^{\mathrm{a}}$ edición en español ed.). Bogotá DC: Legis. 
Rojas Novoa, S., \& Baldeón Güere, A. (2007). Nociones Principales sobre los Convenios para evitar la doble imposición. Actualidad Empresarial(134).

Romero Flor, L. M. (Mayo de 2006). E problema de la Doble Imposición y los métodos para su eliminacion en el Impuesto sobre Sociedades Español. Obtenido de docm.jccm:

http://docm.jccm.es/portaldocm/descargarArchivo.do?ruta=Revista40.pdf\&tipo $=$ rutaRevistas

SERVICIO DE IMPUESTOS INTERNOS. (18 de enero de 2017). Obtenido de http://www.sii.cl/normativa_legislacion/jurisprudencia_administrativa/ley_impu esto_renta/2017/ja109.htm

SUNAT, I. N. (25 de 05 de 2015). i023-2015 INFORME N. ${ }^{\circ} 023-2015-$ SUNAT/5D0000. Obtenido de SUNAT: http://www.sunat.gob.pe/legislacion/oficios/2015/informe-oficios/i023-2015.pdf

SUNAT, I. N. (11 de 12 de 2015). i169-2015 INFORME N. ${ }^{\circ} 0169-2015-$ SUNAT/5D0000 . Obtenido de SUNAT: http://www.sunat.gob.pe/legislacion/oficios/2015/informe-oficios/i169-2015.pdf

SUNAT, I. N. (05 de 05 de 2017). i024-2017 INFORME N. ${ }^{\circ}$ 024-2017SUNAT/5D0000. Obtenido de SUNAT: http://www.sunat.gob.pe/legislacion/oficios/2017/informe-oficios/i024-2017.pdf

Velásquez Vainstein, S. (2013). Los criterios de vinculación a propósito de la doble imposición internacional.

Velásquez, V. S. (2012). Obtenido de Los Criterios de Vinculación a propósito de la Doble Imposición Internacional (tesis de maestría): file:///C:/Users/usuario/Downloads/PONTIFICIA\%20UNIVERSIDAD\%20CAT \%C3\%93LICA\%20DEL\%20PER\%C3\%9A\%20ESCUELA\%20DE\%20POSGR ADO.pdf

Villagra, C. R. (junio de 2008). Los convenios para evitar la doble imposicion y prevenir la evasión fiscal. Obtenido de ifaperu:

http://www.ifaperu.org/uploads/articles/316_01_manual_cdi.pdf 